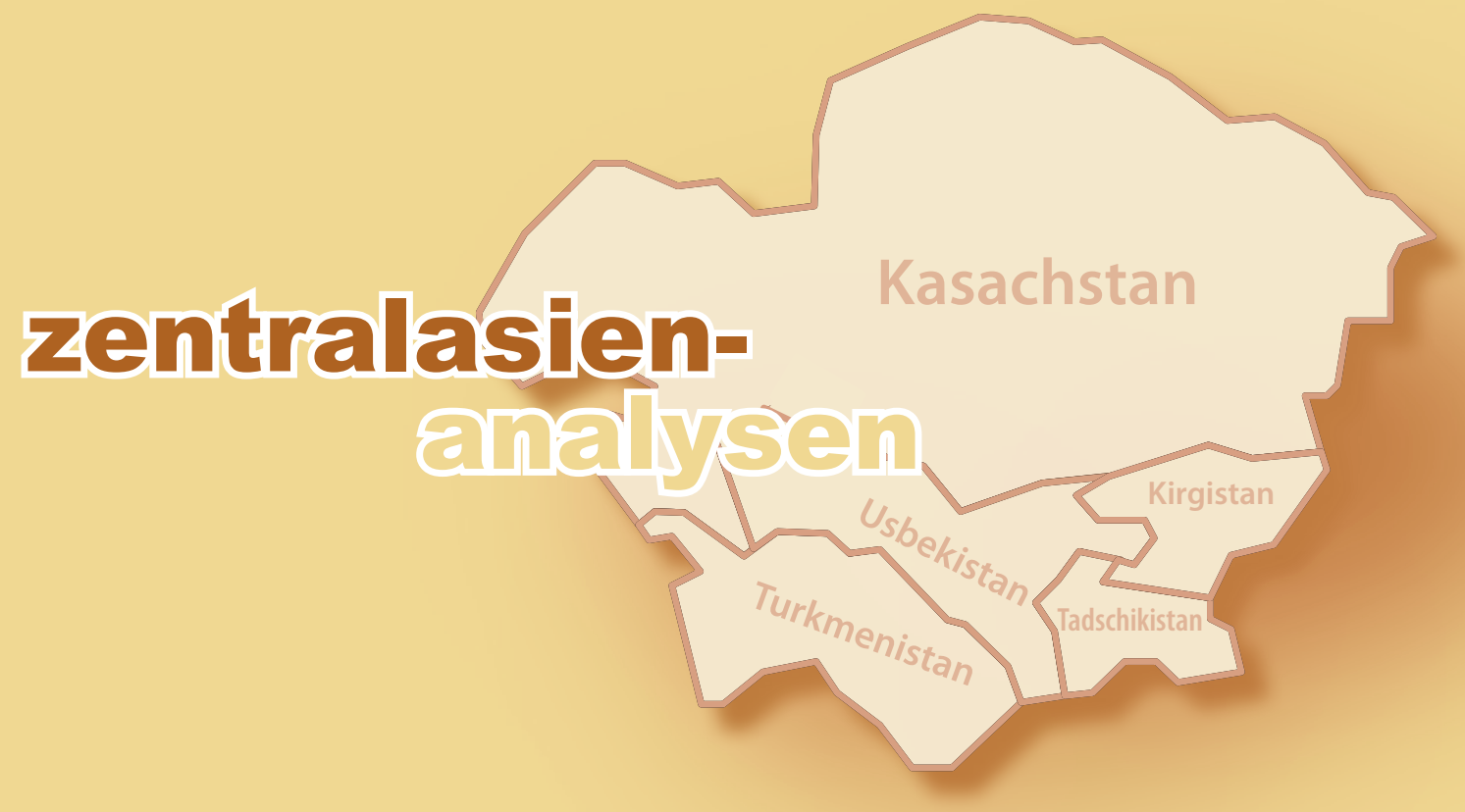

\title{
SÄKULARER STAAT UND ISLAMISMUS IN TADSCHIKISTAN
}

\section{ANALYSE}

Säkularer Staat und Islamismus in Tadschikistan

Von Musaffar Olimow und Saodat Olimowa, Duschanbe

- TABELLEN UND GRAFIKEN ZUM TEXT

Ergebnisse der Meinungsumfragen der Autoren zur Stellung der Religion in Tadschikistan

\section{CHRONIK}

22. September - 19. Oktober 2018

Kasachstan

Kirgistan

Tadschikistan

Turkmenistan

Usbekistan

Leibniz-Institut für Ost- und Südosteuropaforschung
Zentrum für Osteuropa- und internationale Studien (ZOiS) $\mathrm{gGmbH}$ 


\title{
Säkularer Staat und Islamismus in Tadschikistan
}

\author{
Von Musaffar Olimow und Saodat Olimowa, Duschanbe
}

\section{Zusammenfassung}

Über die Gefährdung der zentralasiatischen Staaten durch islamistische Strömungen bestehen ganz unterschiedliche Einschätzungen, die u. a. auf unterschiedlichen Definitionen und politischen Positionen beruhen. Für ein begründetes Urteil ist genaueres Wissen über die gesellschaftlichen Einstellungen gegenüber dem Islam und seine Rolle im politischen Leben in den einzelnen Staaten nötig. Daher wird im folgenden Text eine bestimmte Ausprägung des Säkularismus in Zentralasien am Beispiel Tadschikistans untersucht. Auf der Grundlage eigener soziologischer Umfragen über die öffentliche Meinung zur Rolle des Islam in der Politik, die religiöse Praxis und die Religionspolitik sowie die Beziehungen des säkularen Staats zum politischen Islam kommen die Autoren zu dem Ergebnis, dass zwischen den Positionen des Staates und der Gesellschaft zu religiösen Fragen eine wachsende Kluft zu beobachten ist. Darüber hinaus gibt es auch Unterschiede zwischen der jungen und den älteren Generationen in ihren Ansichten über eine säkulare Weltanschauung bzw. den Islamismus.

$\mathrm{D}$ ie Überzeugung, dass politische islamische Bewegungen und religiöse Radikalisierung zu den zentralen Sicherheitsrisiken in Zentralasien zählen, ist weit verbreitet. Meistens werden in diesem Zusammenhang Zahlen über aus Zentralasien stammende [islamistische] Kämpfer, die an weltweiten Terrorakten beteiligt sind, sowie offizielle Statistiken über extremistische und terroristische Straftaten angeführt. Ein Vergleich mit anderen islamisch geprägten Regionen der Welt hinsichtlich des Spektrums, der Stärke und Aktivität politischer islamischer Bewegungen, der Zahl ihrer Kämpfer und ihrer Bewaffnung sowie des Charakters und der Frequenz ihrer Aktivitäten (Terroranschläge eingeschlossen) zeigt andererseits, dass die Situation in den Ländern Zentralasiens eigentlich als ruhig bezeichnet werden kann.

Teilweise ist diese widersprüchliche Einschätzung in einer unterschiedlichen Verwendung von Definitionen und Begriffen begründet. In den zentralasiatischen Republiken existiert ein spezifisches Verständnis von politischem Islam und religiöser Radikalisierung. Unter letzterer versteht man: a) eine Intensivierung des religiösen Lebens im Rahmen der bestehenden Ausprägung des Islam; b) das Auftreten neuer religiöser Strömungen und Auslegungen (manchmal auch als »anderer Islam« bezeichnet), und c) diverse Formen eines politischen Islam im weitesten Sinne. Islamwissenschafler und Soziologen verbinden diese Erscheinungen jedoch nicht direkt mit einer Radikalisierung, sondern sehen sie als Teil eines Prozesses, in dem die Rolle und Funktion von Religion im Leben postsowjetischer Gesellschaften wiederbelebt wird. Diese unterschiedlichen Begriffsbestimmungen führen zu sehr unterschiedlichen Einschätzungen der Sicherheitsrisiken.

In den letzten Jahren sind von Wissenschaftlern wie Emanuel Karagiannis, Michael Taarnby und anderen verschiedene Studien zum Extremismus und zu radika- len Bewegungen in Tadschikistan durchgeführt worden. Meistens kommen die Autoren zu dem Schluss, dass politischer Islam und Radikalisierung zwar ein Gefährdungspotential darstellen, dieses aber unklar ist und noch gründlicherer Untersuchung bedarf. Ihrer Ansicht nach liegen die Wurzeln der religiösen Radikalisierung in den unbefriedigenden sozioökonomischen Verhältnissen und in der schwachen Regierungsführung, in der Geschichte des politischen Islam und der islamischen Parteien in der Republik Tadschikistan, im Import von Ideen aus den Ländern des Nahen und Mittleren Ostens und Südasiens sowie im niedrigen Niveau der religiösen Bildung.

Zugleich wird allgemein anerkannt, dass die Gefahr einer religiösen Radikalisierung in Tadschikistan sehr hoch ist, weil das Land eine rund $1.300 \mathrm{~km}$ lange gemeinsame Grenze mit Afghanistan hat und es einige Gruppierungen mit engen Verbindungen zu verschiedenen internationalen islamistischen Strömungen gibt. Diese Einschätzung entspricht der Position der staatlichen Organe der Republik Tadschikistan, sie sehen die Radikalisierung des Islam als eines der zentralen Sicherheitsprobleme und bezeichnen Afghanistan und Iran als wichtigste Quellen dieser Bedrohung.

Es gibt aber auch Experten, die der Auffassung sind, dass die zunehmende religiöse Radikalisierung in Zentralasien ein Mythos sei, der im Kampf der autoritären zentralasiatischen Regime gegen die Opposition entstanden ist, der unter der Flagge des Kampfes gegen radikale islamische Bewegungen und für den Erhalt des säkularen Staats geführt wird. Die Frage, ob radikale religiöse Bewegungen tatsächlich die säkularen Regime in Zentralasien bedrohen, muss auf dieser Ebene daher offenbleiben. Um ein klareres Bild zu erhalten, muss man genauer betrachten, wie sich die Gesellschaft gegenüber islamistischen Bewegungen verhält und welche 
Rolle der Islam im politischen Leben der zentralasiatischen Staaten spielt.

\section{Religiosität in Tadschikistan: empirische Befunde}

Die empirische Basis für den vorliegenden Beitrag bilden Ergebnisse repräsentativer landesweiter Meinungsumfragen in den Jahren 2014 (2.000 Befragte) und 2016 (1.200 ausschließlich junge Menschen) sowie Experteninterviews mit führenden Vertretern des Islam und Fachleuten, die zwischen 2013 und 2017 in Tadschikistan stattgefunden haben.

Die Umfrage von 2014 ergab folgendes Bild der religiösen Situation in der Republik Tadschikistan: 99\% der Bevölkerung glauben an Gott, und $96 \%$ orientieren sich in ihren Entscheidungen mehr oder weniger stark an ihrem Glauben. Im Land sind folgende Glaubensrichtungen vertreten: $98 \%$ bezeichnen sich als Muslime, $0,5 \%$ als orthodoxe Christen, 0,2\% als Atheisten und über $1 \%$ gehören zu diversen anderen Konfessionen (anderen christlichen Kirchen, Bahai, AhmadiyyaMuslime, Zoroastrier). $87 \%$ der Muslime sind Sunniten, 3,2\% Ismailiten, 1,4\% Schiiten, und 6-7\% bezeichnen sich einfach nur als Muslime. Ca. zwei Drittel der Muslime praktizieren ihren Glauben: $50 \%$ beten fünf Mal täglich - was als Indiz für starke Religiosität gelten kann, 76\% fasten während des Ramadan regelmäßig und $74 \%$ besuchen mehr oder weniger regelmäßig eine Moschee.

Nach offiziellen Angaben (Stichtag 1. Januar 2017) gab es auf dem Gebiet der Republik Tadschikistan 3.900 offiziell registrierte Moscheen, darunter 48 Zentrale Freitagsmoscheen, 326 Freitagsmoscheen und 3.551 Moscheen, in denen fünf Mal täglich zum Gebet gerufen wird. Außerdem sind drei ismailitische Gebetshäuser und 69 nicht-muslimische religiöse Organisationen offiziell registriert und aktiv.

\section{Das Verhältnis von Islam und Staat im Spiegel der öffentlichen Meinung}

Unsere Untersuchungen haben gezeigt, dass der Islam im Verlauf der nunmehr über 25-jährigen postsowjetischen Übergangsperiode in den weltanschaulichen und moralischen Wertvorstellungen der Bürger Tadschikistans wieder seine frühere [prägende] Position in den Bereichen Ehe und Familie, in den Alltagspraktiken und im gesamtgesellschaftlichen Leben eingenommen hat. In den letzten Jahren gab es Versuche, ein islamisches Bankwesen zu entwickeln. Gleichzeitig hat die sowjetisch geprägte Gesetzgebung in den Bereichen Wirtschaft, Recht, Verwaltung und Politik weiterhin Geltung. Die von der Sowjetunion geerbten Spielregeln bestehen fort.
Unsere Befragungsergebnisse zeigen, dass die Bevölkerung Tadschikistans sich überwiegend zu lokalen Ausprägungen des Hanafismus bekennt; dieser erkennt die Trennung von weltlicher und religiöser Sphäre an und sieht die Regierungsvollmachten ausschließlich bei der weltlichen Macht. Allerdings sollten sich die weltlichen Machthaber nach Ansicht der tadschikischen Bevölkerung an der islamischen Ethik und deren Moralvorstellungen orientieren.

Diese Ambivalenz spiegelt sich in der öffentlichen Meinung deutlich wieder. Eine Analyse der Frage nach den Wechselbeziehungen zwischen Islam und Regierung (Daten von 2014) zeigt, dass es in der tadschikischen Gesellschaft zwei etwa gleich starke Hauptgruppen gibt: Zum einen diejenigen, die der Ansicht sind, dass der Islam in Politik und Religion keinerlei Rolle spielen sollte und in der staatlichen Politik nichts zu suchen hat (45\%). Auf der anderen Seite jene, die angeben, dass politische Führer im säkularen Staat Tadschikistan islamische Rechts- und Moralvorstellungen berücksichtigen müssen. Sie halten es auch für sinnvoll, in die säkulare Gesetzgebung einzelne Normen der Scharia einzufügen, vor allem im Ehe- und Familienrecht. Lediglich 1-2\% der Befragten meinen, dass die Gesetzgebung auf der Scharia basieren sollte. Insgesamt sind $80 \%$ der Ansicht, dass der Staat in Tadschikistan sich an islamische Wertvorstellungen halten sollte.

Wenn es um die Rolle und den Platz islamischer Führer in der Politik geht, lassen sich drei beinahe gleich große Gruppen identifizieren: a) Eine Gruppe meint, dass religiöse Führer überhaupt keine Rolle in der Politik spielen sollten (28\%). b) Eine zweite Gruppe vertritt die Ansicht, dass religiöse Führer sich zu politischen Fragen äußern und den politischen Führern Ratschläge auf der Grundlage islamischer Positionen erteilen sollten (27\%). c) Die dritte Gruppe ist der Meinung, dass religiöse Führer sich gleichberechtigt in der Politik betätigen können sollten (26\%). Die Mehrheit der Befragten (65\%) vertritt die Ansicht, dass es in Tadschikistan politische islamische Parteien auf Grundlage eines gemäßigten Islam geben sollte.

Bei der Untersuchung der öffentlichen Meinung zum Thema Beziehungen zwischen Islam und Staat sind auch die Unterschiede zwischen den Generationen zu beachten. Die weltanschaulichen Transformationsprozesse nach dem Zerfall der Sowjetunion und die Abkehr von der sowjetischen Ideologie und vom Atheismus in der Bevölkerung Tadschikistans dauern an. Während der Sowjetzeit war die Religiosität unter den Vertretern der älteren Generation am stärksten ausgeprägt. Der Anteil praktizierender Gläubiger unter jungen Leuten war weitaus geringer. Diese Situation hat sich im ersten Jahrzehnt nach dem Zerfall der Sowjet- 
union radikal verändert. In den 2000er Jahren beachteten die Jüngeren die religiösen Normen weitaus strenger als ihre Eltern und mehr noch als ihre »sowjetischen Großväter«, unter denen es viele überzeugte Kommunisten gab. In den letzten Jahren hat sich das übliche Muster, dass die junge Generation weniger religiös ist als die ältere, wieder durchgesetzt. Das hat mit dem Generationswechsel zu tun: die Alten - die Erbauer des Sozialismus in Tadschikistan - verschwinden, und die während der Sowjetzeit geborenen Erwachsenen versuchen, sich ein umfassendes islamisches Weltbild anzueignen. Insgesamt spielt die Religion in der Weltanschauung der tadschikischen Jugend aber eine größere Rolle als bei ihren Eltern.

Um herauszufinden, wie stark junge Menschen zwischen 14-29 Jahren den Säkularismus bzw. die Errichtung eines islamischen Staats unterstützen, stellten wir ihnen die Frage nach den Perspektiven eines weltlichen oder eines islamischen Staates in der Republik Tadschikistan. Die überwiegende Mehrheit, nämlich $62 \%$, sprach sich für den Erhalt des säkularen Staats aus. Fast ein Viertel der Befragten ist für die Einführung einzelner Gesetze auf Basis der Scharia, und nur 6\% der Jugendlichen wünschen sich, dass Tadschikistan ein islamischer Staat wird.

\section{Staatliche Religionspolitik}

Während des Bürgerkrieges (1992-1997) gehörte die oppositionelle islamische Bewegung zu den Konfliktparteien. Nach dem Friedensabkommen von 1997 wurde in Tadschikistan eine liberale Religionspolitik umgesetzt. In dieser Zeit wurde die tadschikische Definition des Säkularismus entwickelt, die auf die Trennung zwischen Staat und religiösen Organisationen, aber nicht zwischen Staat und Religion, abzielte. Die normativ-rechtliche Grundlage und die Gesetzgebung zur Gewissensfreiheit und zu den religiösen Organisationen wurden erarbeitet, eine aktive und funktionsfähige islamische politische Partei war im Parlament vertreten. Auch die Regulierung des religiösen Lebens wurde auf eine systematische Grundlage gestellt und durch die Einrichtung des Komitees für Religion und nationale Traditionen, Feste und Riten (angesiedelt bei der tadschikischen Regierung) und des Zentrums für Islamwissenschaft beim Präsidenten der Republik unterstützt. Das Zentrum hat auch einen nichtstaatlichen »Rat islamischer Gelehrter« (schuro-i ulamo), der aus 25 islamischen Autoritäten besteht. Der Vorsitzende dieses Rats ist gleichzeitig auch Vorsitzender des Zentrums für Islamwissenschaft. Zu den Aufgaben des Rats gehört es, Rechtsauskünfte zu Religionsfragen (fatwa) zu geben, religiöse Streitigkeiten zu schlichten und die Muslime Tadschikistans im Geiste der moralischen Normen des
Islam, des Patriotismus, der Toleranz und der Achtung anderer Religionen zu unterweisen.

Das Jahr 2009 wurde in Tadschikistan zum Jahr des großen Imam (imam al-azam) Abu Hanifa erklärt und gleichzeitig die hanafitische Richtung (madhhab) des sunnitischen Islam zur offiziellen Glaubenslehre des Landes erklärt. Der Hanafismus ist weltweit die am stärksten verbreitete und liberalste Rechtsschule des Islam; sie erkennt die Existenz einer weltlichen Macht und weltlicher Staaten an. Dennoch stellte die Anerkennung des Hanafismus als offizielle Lehre in Tadschikistan faktisch eine Absage an den Verfassungsgrundsatz der Trennung von Staat und Religion dar. Diese Entwicklung vollzog sich im Kontext der Stärkung der Präsidialmacht, einer Zunahme autoritärer Tendenzen und eines immer härteren Kampfes mit der politischen, oft religiös geprägten, Opposition.

Seither hat sich ein Wandel vollzogen - die staatliche Religionspolitik verschärft sich von Jahr zu Jahr. Der Staat mischt sich immer aktiver in das religiöse Leben der Muslime ein und beansprucht die Definitionsmacht in Bezug auf den »wahren Islam». Beim Präsidenten der Republik wurde ein Zentrum für Islamwissenschaften gegründet und der Koran ins Tadschikische übersetzt und großzügig verteilt. In der Schule wurde das Fach "Religionsgeschichte» eingeführt und die Moscheen mussten sich neu registrieren lassen, was zur Schließung von über 1.500 Moscheen führte. Dieser Prozess der Schließung von Moscheen hält bis heute an.

Entsprechend der offiziellen Version des Islam, die vom Komitee für Religionsangelegenheiten und nationale Traditionen, Feste und Riten, vom Zentrum für Islamwissenschaft und vom Rat der islamischen Gelehrten ausgearbeitet wurde, wurden die Dogmatik, die Regeln für Gebet und Predigt und die religiösen Rituale vereinheitlicht. 2009 wurde ein neues Gesetz über Gewissensfreiheit und religiöse Organisationen verabschiedet, anschließend das Gesetz über Regulierung von Riten und Traditionen. Das Gesetz "Über die Verantwortung der Eltern bei der Erziehung und Ausbildung ihrer Kinder« (2011) verpflichtet die Erziehungsberechtigten, die Teilnahme Minderjähriger an religiösen Aktivitäten zu unterbinden, außerdem ist Personen unter 18 Jahren der Besuch einer Moschee verboten. Die als radikal bezeichneten Organisationen Hizb ut-Tahrir (Partei der Befreiung) und Tabligi Dschamaat (Missionsgesellschaft), salafitische Bewegungen und andere wurden verboten. Später wurde eine Verordnung erlassen, auf deren Grundlage staatliche Stellen sowohl die Themen der Freitagspredigten bestimmen als auch die VorbeterPrediger (imam chatib) in den Moscheen zertifizieren. Außerdem wurde für letztere ein Sammelband mit Predigten und 2014 ein staatliches Handbuch herausgege- 
ben. 2015 wurde schließlich die Partei der Islamischen Wiedergeburt (PIWT) verboten; in allen Moscheen wurden Videokameras installiert, Staatsangestellten wurde der Besuch der Freitagspredigten verboten, und es wurden massenhaft und systematisch Razzien durchgeführt, um sichtbare Symbole des Islam wie Bärte und Kopftücher zu bekämpfen. Ziel all dieser Maßnahmen war es, religiöse Radikalisierung, Extremismus und Terrorismus abzuwehren.

Unsere Meinungsumfragen zeigen, dass die tadschikische Bevölkerung der Verschärfung der Religionspolitik insgesamt wohlwollend gegenübersteht; allerdings ist die Unterstützung für die Maßnahmen der Regierung in den verschiedenen Altersgruppen und sozialen Schichten nicht einheitlich. In den Generationen über 30 Jahre gibt es zwei unterschiedlich große Gruppen: zwei Drittel (65\%) unterstützen den Staat, während fast ein Drittel gegen die staatliche Religionspolitik ist. In der jungen Generation (14-29 Jahre) unterstützt weniger als die Hälfte die Regierung, ein Viertel ist dagegen und ein Drittel hat keine Meinung dazu. Allerdings meinen mehr als $60 \%$ der jungen Leute, dass Religion im gesellschaftlichen Leben eine größere Rolle spielen sollte. Diese Position vertreten vor allem Männer, die auf dem Lande leben, während Frauen sowohl in der Stadt wie auf dem Land weniger zu dieser Meinung neigen.

\section{Fazit}

Die Ergebnisse unserer Meinungsumfragen zum Thema Islam und zum Verhältnis von Staat und Religion in Tadschikistan sowie die Analyse der staatlichen Religionspolitik zeigen, dass sich die Kluft zwischen Gesellschaft und Staat in religiösen Fragen vertieft.
Man kann die Ergebnisse der Meinungsumfragen unterschiedlich interpretieren, doch darf man eines der zentralen Probleme in Zentralasien nicht ignorieren: die Suche nach einer Balance zwischen Sicherheitsinteressen und der menschlichen Dimension, konkret formuliert, zwischen der Abwehr eines gewaltbereiten Extremismus und der Achtung der Menschenrechte. In seinem Bemühen, die innere Sicherheit zu garantieren, schränkt der Staat die Menschenrechte, unter anderem die Meinungs- und Religionsfreiheit, immer mehr ein. Die heute bestehende Kluft zwischen der Religionspolitik und den Wertvorstellungen der Gesellschaft ist ziemlich gefährlich, denn Menschenrechte und Sicherheit sind zwei Seiten ein und derselben Medaille. Werden die Menschenrechte systematisch verletzt, ist die Gesellschaft grundsätzlich kein sicherer Ort mehr.

Die harte, auf Verbote setzende Religionspolitik der tadschikischen Regierung und die nicht gerechtfertigte Einmischung des Staates in das religiöse, private und gesellschaftliche Leben rufen gegenteilige Reaktionen hervor: Sie treiben einen Teil der jungen Generation dazu, sich radikalen Ideen zuzuwenden, und verschärfen die Spannungen in der Gesellschaft. Die Menschen verbergen ihre religiösen Überzeugungen und verlieren das Grundvertrauen in den Staat und die Gesellschaft. In diesem angstbesetzten sozialen Klima sind junge Muslime der Propaganda radikaler Islamisten im globalen Internet schutzlos ausgesetzt.

Aus dem Russischen von Brigitte Heuer

Über die Autoren:

Prof. Dr. Musaffar Olimow, Historiker, und Dr. phil. Saodat Olimowa, Unabhängiges Forschungszentraum »Sharq/ Oriens«, Duschanbe, Tadschikistan.

\section{Lesetipps:}

- Paul Goble, Tajikistan, Most Muslim Country in Central Asia, Struggles to Rein In Islam, Jamestown Eurasia Daily Monitor, 6.2.2018, = <https://jamestown.org/program/tajikistan-muslim-country-central-asia-struggles-rein-islam/>

- Tajikistan Converts 2,000 Mosques Into Public Facilities, Eurasianet, 6.2.2018, = <https://eurasianet.org/ tajikistan-converts-2000-mosques-into-public-facilities>

- Andrea Schmitz, Islam in Tadschikistan. Akteure, Diskurse, Konflikte, SWP Studie, März 2015, = <https://www. swp-berlin.org/fileadmin/contents/products/studien/2015_S06_smz.pdf>

- Edward Lemon, Transforming Tajikistan: how the Rahmon regime turned religion into a site of struggle, ODR. Russian and beyond, 4.9.2018, = <https://www.opendemocracy.net/od-russia/edward-lemon/transforming-tajikistan-islam > 


\section{Ergebnisse der Meinungsumfragen der Autoren zur Stellung der Religion in Tadschikistan}

Grafik 1: Welcher Religion/Glaubensrichtung hängen Sie an? (\% gesamt)

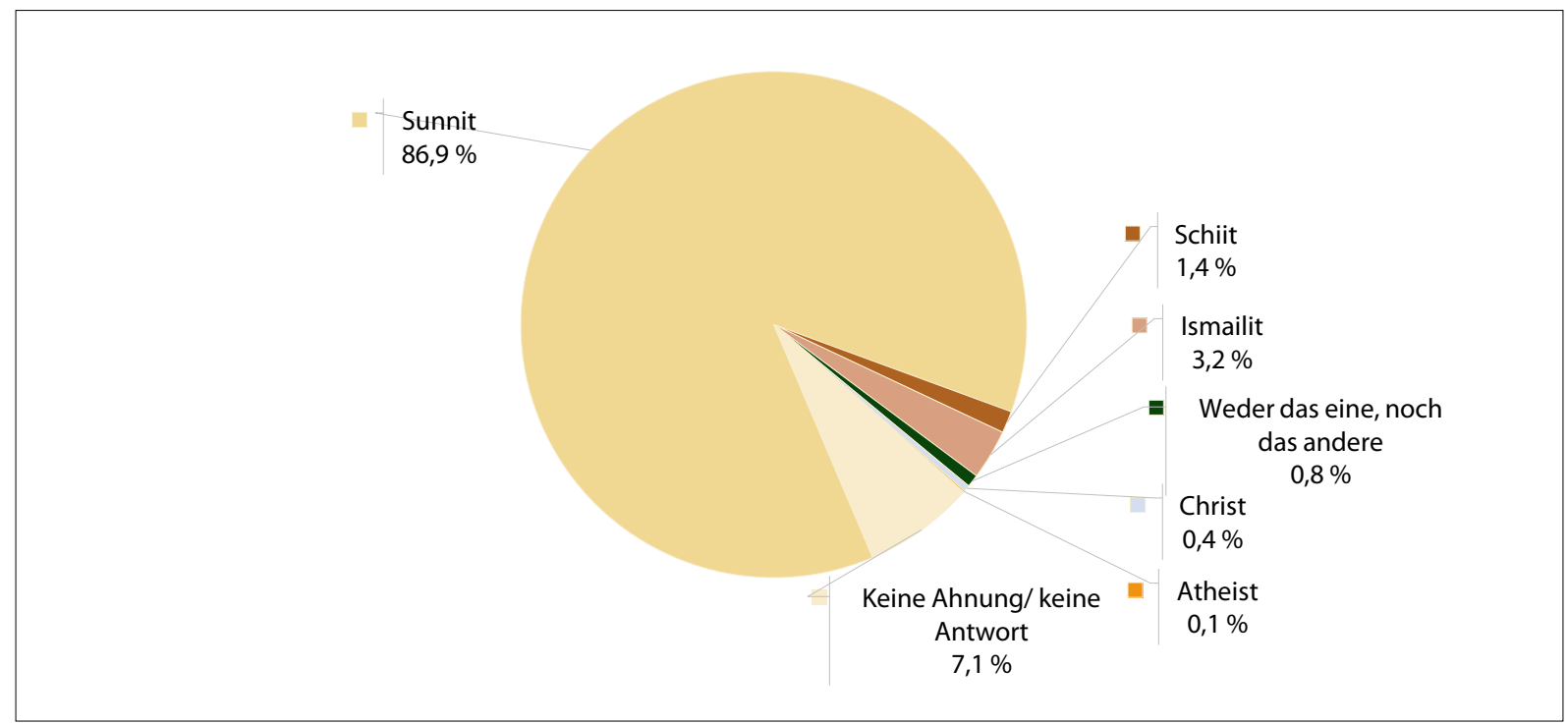

Quelle: 2.000 repräsentativ ausgewählte Befragte (2014) und Experteninterviews (2013-17), durchgeführt von Prof. Dr. Musaffar Olimow und Dr. phil. Saodat Olimowa

Grafik 2: Welche Rolle sollte Religion in der Politik spielen? (\% gesamt)

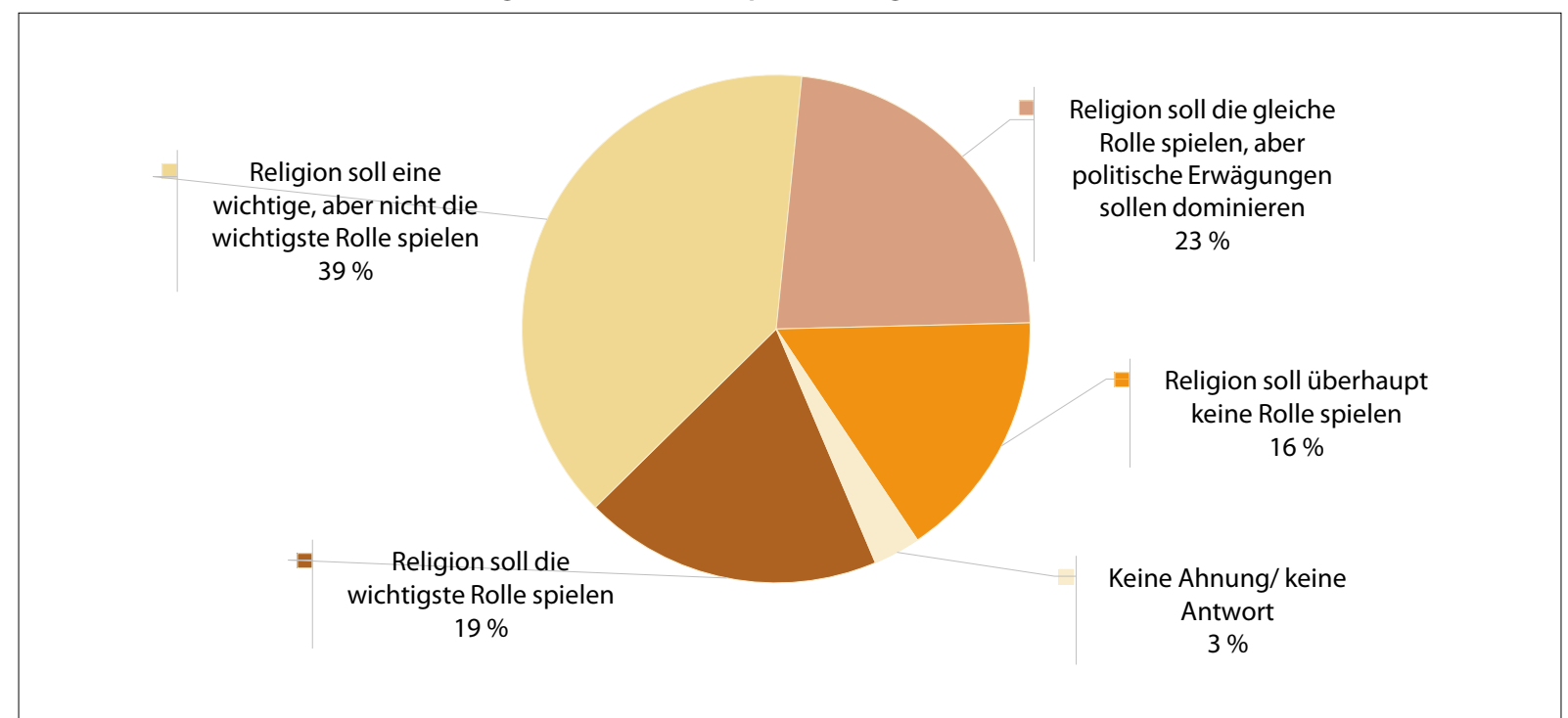

Quelle: 2.000 repräsentativ ausgewählte Befragte (2014) und Experteninterviews (2013-17), durchgeführt von Prof. Dr. Musaffar Olimow und Dr. phil. Saodat Olimowa 
Grafik 3: Inwieweit stimmen Sie folgender Aussage zu: „Die aktuelle Situation Tadschikistans würde sich verbessern, wenn religiöse Überzeugungen eine wichtige Rolle im Handeln unserer Führer spielen würden«? (\% gesamt)

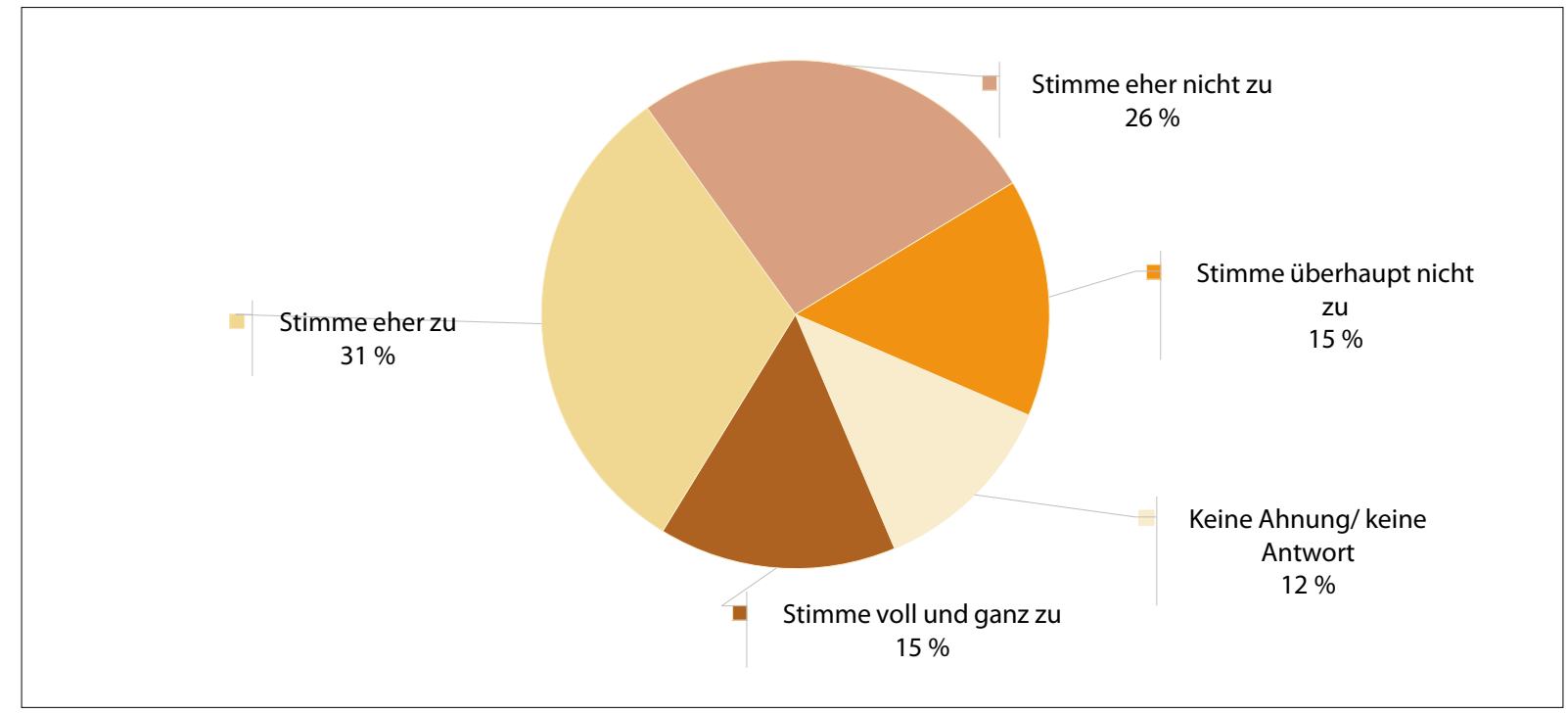

Quelle: 2.000 repräsentativ ausgewählte Befragte (2014) und Experteninterviews (2013-17), durchgeführt von Prof. Dr. Musaffar Olimow und Dr. phil. Saodat Olimowa 


\section{September - 19. Oktober 2018}

\section{Kasachstan}

\begin{tabular}{|c|c|}
\hline 25.9 .2018 & $\begin{array}{l}\text { Nach Angaben des stellvertretenden Ministers für soziale Entwicklung, Berik Aryn, sind nach einer umfassen- } \\
\text { den Überprüfung alle Kindergärten, die Religionsunterricht angeboten haben, geschlossen worden. }\end{array}$ \\
\hline 27.9.2018 & $\begin{array}{l}\text { Präsident Nursultan Nasarbajew befördert den bisherigen stellvertretenden Direktor des Auslandsgeheimdiens- } \\
\text { tes Syrbar, Isatai Sartajew, zum Chef des Dienstes. Sein Vorgänger, Gabit Baidschanow, war am 19.9.2018 zum } \\
\text { Berater des Präsidenten und Sekretär des Sicherheitsrates berufen worden. }\end{array}$ \\
\hline 27.9.2018 & $\begin{array}{l}\text { In Aktau (Gebiet Mangystau) wird der französische Journalist Vincent Prado festgenommen, der zu den töd- } \\
\text { lichen Protesten in Schanaösen } 2011 \text { recherchiert hatte, bei denen mindestens } 16 \text { Demonstranten von Sicher- } \\
\text { heitskräften erschossen worden waren. Reporter ohne Grenzen fordert die unverzügliche Freilassung Prados. }\end{array}$ \\
\hline 27.9 .2018 & $\begin{array}{l}\text { Obermufti Serikbai hajji Oras fordert während eines Besuchs in Aktobe in einer öffentlichen Ansprache alle } \\
\text { Eltern auf, darauf zu achten, dass ihre Kinder die schulischen Anforderungen erfüllen und bittet, dem Verbot } \\
\text { des Tragens religiöser Kleidung mit Verständnis zu begegnen. }\end{array}$ \\
\hline 28.9.2018 & $\begin{array}{l}\text { Präsident Nasarbajew nimmt am jährlichen Treffen der Staatsoberhäupter der GUS-Mitgliedsstaaten in } \\
\text { Duschanbe teil. Am Rande des Gipfels führt er bilaterale Gespräche mit seinem tadschikischen Amtskollegen } \\
\text { Emomali Rachmon sowie mit dem armenischen Premierminister Nikol Paschinjan. Am Vortag hatte Außen- } \\
\text { minister Kairat Abdrachmanow bereits am Rat der GUS-Außenminister teilgenommen. }\end{array}$ \\
\hline 29.9 .2018 & $\begin{array}{l}\text { Außenminister Abdrachmanow hält eine Rede über nukleare Abrüstung und Nichtverbreitung von Atomwaf- } \\
\text { fen bei der } 73 \text {. Sitzung der UN-Vollversammlung in New York. Am Rande der Veranstaltung trifft Abdrach- } \\
\text { manow auch mit UN-Generalsekretär António Guterres zu Gesprächen zusammen. }\end{array}$ \\
\hline 29.9.2018 & $\begin{array}{l}\text { Präsident Nasarbajew ordnet per Dekret die Einrichtung einer Sonderwirtschaftszone im Gebiet Turkestan } \\
\text { (bis Juli } 2018 \text { Südkasachstan) an. Im Rahmen eines internationalen Investitions- und Tourismusforums wer- } \\
\text { den } 19 \text { Verträge in Höhe von insgesamt 1,7 Mrd. US-Dollar zwischen der Gebietsverwaltung und ausländi- } \\
\text { schen Investoren unterzeichnet. }\end{array}$ \\
\hline 1.10 .2018 & $\begin{array}{l}\text { In Schanaösen nehmen Hunderte Menschen an der Beerdigung des Aktivisten Maksat Dosmagambetow teil, } \\
\text { der zwei Tage zuvor einem Krebsleiden erlegen war. Dosmagambatow war } 2012 \text { wegen der Organisation der } \\
\text { Ölarbeiterproteste im Dezember } 2011 \text { in Schanaösen zu sechs Jahren Haft verurteilt worden und hatte sich } \\
\text { mehrmals über Folter im Gefängnis beschwert. }\end{array}$ \\
\hline 1.10 .2018 & $\begin{array}{l}\text { Auf dem Gelände der 40. Militärbasis Otar finden gemeinsame Manöver der CSTO-Mitgliedsstaaten unter } \\
\text { dem Namen »Poisk-2018«statt, an denen mehr als } 3.000 \text { Soldaten und Spezialkräfte teilnehmen. }\end{array}$ \\
\hline 3.10 .2018 & $\begin{array}{l}\text { Verteidigungsminister Nurlan Jermekbajew empfängt seine indische Amtskollegin Nirmala Sitharaman zu } \\
\text { Gesprächen über die militärische Zusammenarbeit im Rahmen der UN-Mission im Libanon (UNIFIL). }\end{array}$ \\
\hline 4.10 .2018 & $\begin{array}{l}\text { RFE/RL meldet, dass mehrere Dutzend aus China stammende ethnische Kasachen im deutschen Konsulat in } \\
\text { Almaty eine Petition an Bundeskanzlerin Angela Merkel übergeben haben, in der sie Unterstützung im Kampf } \\
\text { um die Freilassung ihrer Verwandten aus Umerziehungslagern in der chinesischen Provinz Xinjiang fordern. } \\
\text { Bei einer anschließenden Pressekonferenz berichten einige von ihren vermissten Familienmitgliedern und zei- } \\
\text { gen Fotos. }\end{array}$ \\
\hline 5.10 .2018 & $\begin{array}{l}\text { In seiner zweiten großen Ansprache an das Volk in diesem Jahr kündigt Präsident Nasarbajew u. a. die Erhö-- } \\
\text { hung des Mindestlohns um } 50 \% \text { sowie Verbesserungen des Gesundheitssystems an. Für die Realisierung der } \\
\text { vorgeschlagenen Reformen stehen 1,8 Billionen Tenge (ca. 4,1 Mrd. US-Dollar) zur Verfügung. }\end{array}$ \\
\hline 5.10 .2018 & $\begin{array}{l}\text { Das Migrationskomitee verweigert der ethnisch kasachischen chinesischen Staatsbürgerin Sayragul Sauytbai, } \\
\text { die im April aus China geflohen war und in den vergangenen Monaten öffentlich über sogenannte Umerzie- } \\
\text { hungslager in der chinesischen Provinz Xinjiang berichtet hatte, politisches Asyl. }\end{array}$ \\
\hline 6.10 .2018 & $\begin{array}{l}\text { Innenminister Kalmuchanbet Kassymow nimmt gemeinsam mit seinen Amtskollegen aus Kirgistan, Tadschi- } \\
\text { kistan und Usbekistan sowie den Leitern der zentralen Abteilungen der jeweiligen Innenministerien und der } \\
\text { Grenzdienste am ersten gemeinsamen Treffen der Innenminister der zentralasiatischen Staaten im kirgisischen } \\
\text { Tscholpon-Ata (Gebiet Issyk-Kul) teil. Themen des Treffens sind vor allem der Kampf gegen die organisierte } \\
\text { Kriminalität, Extremismus und Terrorismus sowie die Gewährleistung der öffentlichen Ordnung und Sicher- } \\
\text { heit in den Grenzgebieten. }\end{array}$ \\
\hline
\end{tabular}




\begin{tabular}{|c|c|}
\hline 8.10 .2018 & $\begin{array}{l}\text { Ein Gericht in Almaty verurteilt den ehemaligen Bürgermeister der Stadt, Wiktor Chrapunow, und seine Ehe- } \\
\text { frau zu } 17 \text { bzw. } 14 \text { Jahren Gefängnis wegen Korruption, Amtsmissbrauch, Gründung einer kriminellen Ver- } \\
\text { einigung und Bestechung. Chrapunow, der von } 1997 \text { bis } 2004 \text { Bürgermeister war, lebt seit } 2007 \text { mit seiner } \\
\text { Familie in der Schweiz. }\end{array}$ \\
\hline 8.10 .2018 & $\begin{array}{l}\text { Der Bankier Dschomart Jertajew, der am 8.5.2018 auf Antrag der kasachstanischen Behörden in Moskau wegen } \\
\text { Unterschlagung von } 80 \text { Mio. US-Dollar festgenommen worden war, erhält politisches Asyl in Russland und } \\
\text { wird nicht an Kasachstan ausgeliefert, berichtet die russische Tageszeitung Kommersant. }\end{array}$ \\
\hline 9.10 .2018 & $\begin{array}{l}\text { Präsident Nasarbajew empfängt den serbischen Präsidenten Aleksandar Vučić zu Gesprächen über die bilaterale } \\
\text { Zusammenarbeit in den Bereichen Logistik, Transport und Kommunikation, Verteidigungsindustrie, Land- } \\
\text { wirtschaft, Pharmaindustrie und Bauwesen in Astana. }\end{array}$ \\
\hline 9.10 .2018 & $\begin{array}{l}\text { Am Rande der Sitzung der britisch-kasachstanischen Regierungskommission für Handel und wirtschaftliche } \\
\text { Zusammenarbeit führt Außenminister Abdrachmanow bilaterale Gespräche mit dem britischen Handelsmi- } \\
\text { nister George Hollingbery. }\end{array}$ \\
\hline 9.10 .2018 & $\begin{array}{l}\text { Die Menschenrechtsaktivistin Jelena Semjonowa teilt auf Facebook mit, dass ihr die Ausreise nach Straßburg } \\
\text { verwehrt wurde, wo sie Mitgliedern der Parlamentarischen Versammlung des Europarates (PACE) von Proble- } \\
\text { men weiblicher Gefängnisinsassen in Kasachstan berichten sollte. }\end{array}$ \\
\hline 10.10 .2018 & $\begin{array}{l}\text { Präsident Nasarbajew führt am Rande der Konferenz „20 Jahre OSZE in der Republik Kasachstan: Koopera- } \\
\text { tion und Erfolge« in Astana Gespräche mit OSZE-Generalsekretär Thomas Greminger. }\end{array}$ \\
\hline 10.10 .2018 & $\begin{array}{l}\text { Außenminister Abdrachmanow führt am Rande des ersten Treffens der Vertragsparteien der Wasserkonven- } \\
\text { tion in der asiatischen Region in Astana Gespräche mit dem ungarischen Außenminister, Peter Szijjarto, und } \\
\text { der stellvertretenden Generalsekretärin der UN und Exekutivsekretärin der Wirtschaftskommission für Europa } \\
\text { (UNECE), Olga Algayerova. }\end{array}$ \\
\hline 10.10 .2018 & $\begin{array}{l}\text { Präsident Nasarbajew eröffnet den 6. Internationalen Kongress der Religionsführer der Welt- und traditionel- } \\
\text { len Religionen in Astana, auf dem u. a. Maßnahmen zur Überwindung von Extremismus und Terrorismus } \\
\text { erörtert werden. }\end{array}$ \\
\hline 11.10 .2018 & $\begin{array}{l}\text { Premierminister Bakytdschan Sagyntajew nimmt an der Sitzung des Rates der Regierungschefs der SCO-Mit- } \\
\text { gliedsstaaten in Duschanbe teil, die sich mit aktuellen Aspekten der ökonomischen, kulturellen und humani- } \\
\text { tären Zusammenarbeit auseinandersetzt. }\end{array}$ \\
\hline 11.10 .2018 & $\begin{array}{l}\text { Präsident Nasarbajew entlässt den Direktor des Staatlichen Sicherheitsdiensts, Kanat Oraskulow. Nachfolger } \\
\text { wird Asimchan Dschusipow. }\end{array}$ \\
\hline 12.10 .2018 & $\begin{array}{l}\text { Eine Militärdelegation unter der Leitung von Verteidigungsminister Jermekbajew nimmt an der Sitzung des } \\
\text { Rates der Verteidigungsminister der GUS-Staaten in Taschkent teil, bei dem es um den Einsatz von Kommu- } \\
\text { nikationssystemen, die Zusammenarbeit im Bereich der technischen Unterstützung der Streitkräfte bis } 2020 \\
\text { und Übungen des gemeinsamen Luftverteidigungssystems der GUS-Staaten im Jahr } 2019 \text { geht. }\end{array}$ \\
\hline 12.10 .2018 & $\begin{array}{l}\text { Nachdem am Vortag eine Sojus-Rakete, die zwei Astronauten vom Kosmodrom Baikonur zur Weltraumsta- } \\
\text { tion ISS bringen sollte, kurz nach dem Start notlanden musste, suspendiert Russland alle weiteren Sojus-Starts } \\
\text { bis die Hintergründe des Zwischenfalls geklärt wurden. }\end{array}$ \\
\hline 17.10 .2018 & $\begin{array}{l}\text { Im Rahmen seiner Europareise nimmt Präsident Nasarbajew am 12. Asien-Europa-Forum (ASEM) in Brüssel } \\
\text { teil und führt eine Reihe von Gesprächen mit Vertretern der EU-Institutionen, wie z. B. dem Präsidenten der } \\
\text { EU-Kommission, Jean-Claude Juncker, sowie mit dem belgischen König Philippe und dem französischen Prä- } \\
\text { sidenten Emmanuel Macron. Am Vortag hatte er bereits den finnischen Präsidenten Sauli Niinistö und Ver- } \\
\text { treter der finnischen Wirtschaft in Helsinki getroffen. }\end{array}$ \\
\hline
\end{tabular}

\section{Kirgistan}

\begin{tabular}{|l|l|}
\hline 22.9.2018 & Gulbara Kalijewa wird von den 33 Richtern des Obersten Gerichts einstimmig zur neuen Vorsitzenden gewählt. \\
\hline 23.9.2018 & $\begin{array}{l}\text { Die stellvertretende Ministerin für Arbeit und soziale Entwicklung, Suurakan Kadenowa, wird entlassen, nach- } \\
\text { dem sie am 21.9.2018 wegen starker Trunkenheit ihren Flug von Seoul nach Almaty nicht hatte antreten kön- } \\
\text { nen und sich zudem Aufforderungen der Crew widersetzt hatte. }\end{array}$ \\
\hline 25.9.2018 & $\begin{array}{l}\text { Präsident Sooronbai Dscheenbekow nimmt an der Generaldebatte der 73. UN-Vollversammlung in New York } \\
\text { teil. Am Rande führt er Gespräche mit UN-Generalsekretär António Guterres und eröffnet eine Fotoausstel- } \\
\text { lung über Tschingis Aitmatow in der Bibliothek des UN-Hauptgebäudes. Außerdem tritt Kirgistan dem Uni- } \\
\text { versal Health Coverage 2030 Global Compact (UHC2030) bei, der die Reform der öffentlichen Gesundheits- } \\
\text { systeme bis 2030 vorsieht. }\end{array}$ \\
\hline
\end{tabular}




\begin{tabular}{|c|c|}
\hline 25.9.2018 & $\begin{array}{l}\text { Im militärischen Trainingszentrum Edelweiss (Gebiet Issyk-Kul) findet die zweitägige Antiterrorübung »Issyk- } \\
\text { Kul Antiterror 2018« der GUS-Mitgliedsstaaten statt, an der Soldaten, Spezialeinheiten und Vertreter der Straf- } \\
\text { verfolgungsbehörden aus Aserbaidschan, Armenien, Weißrussland, Kasachstan, Russland, Tadschikistan, Usbe- } \\
\text { kistan und Kirgistan teilnehmen. }\end{array}$ \\
\hline 26.9.2018 & $\begin{array}{l}\text { Die Asiatische Entwicklungsbank (ADB) verabschiedet eine neue fünfjährige Länderpartnerschaftsstrategie zur } \\
\text { Förderung des nachhaltigen Wirtschaftswachstums, der regionalen Zusammenarbeit und zur Verbesserung der } \\
\text { Lebensqualität in Kirgistan, die Zuschüsse und staatliche Darlehen in Höhe von } 641 \text { Mio. US-Dollar vorsieht. }\end{array}$ \\
\hline 27.9.2018 & $\begin{array}{l}\text { Der neue Ombudsmann Tokon Mamytow, der bisher das Amt des stellvertretenden Premierministers inne- } \\
\text { hatte, legt im Parlament seinen Amtseid ab, nachdem er am Vorabend in sein neues Amt gewählt worden war. }\end{array}$ \\
\hline 27.9.2018 & $\begin{array}{l}\text { Die Strafverfolgungsbehörden teilen mit, dass ein kirgisischer Staatsbürger wegen der Mitgliedschaft in einer } \\
\text { verbotenen terroristischen Vereinigung festgenommen wurde. Der 23-Jährige soll nach seinem Kampftraining } \\
\text { in Syrien im Jahr } 2013 \text { neue Kämpfer in Kirgistan rekrutiert haben. }\end{array}$ \\
\hline 28.9.2018 & $\begin{array}{l}\text { Präsident Dscheenbekow nimmt am jährlichen Treffen der Staatsoberhäupter der GUS-Mitgliedsstaaten in } \\
\text { Duschanbe teil, bei dem es um aktuelle Fragen der Zusammenarbeit im GUS-Format geht. Am Rande führt } \\
\text { Dscheenbekow bilaterale Gespräche mit seinen russischen und tadschikischen Amtskollegen, Wladimir Putin } \\
\text { und Emomali Rachmon. Außenminister Erlan Abdyldajew hatte am Tag zuvor am Rat der GUS-Außenmi- } \\
\text { nister teilgenommen. }\end{array}$ \\
\hline 1.10 .2018 & $\begin{array}{l}\text { Spezialeinheiten der Armee nehmen an den gemeinsamen militärischen Übungen der CSTO-Mitgliedsstaaten } \\
\text { „Poisk-2018« in Kasachstan teil, die mehr als 3.000 Soldaten und 500 Einheiten militärisches Gerät umfasst. }\end{array}$ \\
\hline 3.10 .2018 & $\begin{array}{l}\text { In Bischkek beginnt die dreitägige Herbsttagung der Parlamentarischen Versammlung der OSZE, an der mehr } \\
\text { als } 160 \text { Abgeordnete aus } 47 \text { Ländern Europas, Asiens und Nordamerikas teilnehmen. Auf der Agenda stehen } \\
\text { Sicherheitsfragen in Zentralasien, der Umgang mit neuen Herausforderungen und Bedrohungen sowie Migra- } \\
\text { tion, Menschenhandel und Umweltprobleme. }\end{array}$ \\
\hline 4.10 .2018 & $\begin{array}{l}\text { Der Oberste Gerichtshof entscheidet, dass die geltende Immunität der ehemaligen Präsidenten des Landes ver- } \\
\text { fassungswidrig ist und weist die Regierung an, entsprechende Gesetzesänderungen vorzunehmen. Nur die bei- } \\
\text { den ehemaligen Präsidenten Rosa Otunbajewa und Almasbek Atambajew haben derzeit den Status als Ex-Prä- } \\
\text { sidenten; Askar Akajew und Kurmanbek Bakijew wurde er nach ihrer Flucht aus Kirgistan entzogen. }\end{array}$ \\
\hline 6.10 .2018 & $\begin{array}{l}\text { In Tscholpon-Ata (Gebiet Issyk-Kul) findet das erste erweiterte gemeinsame Treffen der Innenminister der zen- } \\
\text { tralasiatischen Staaten statt, an dem neben den Innenministern von Kasachstan, Usbekistan, Tadschikistan und } \\
\text { Kirgistan, Kalmuchanbet Kassymow, Pulat Bobodschonow, Ramason Rachimsoda und Kaschkar Dschunuscha- } \\
\text { lijew, auch die Leiter der zentralen Abteilungen der jeweiligen Innenministerien und die Leiter der Grenzdienste } \\
\text { teilnehmen. Im Vordergrund stehen Themen wie der Kampf gegen die organisierte Kriminalität, Extremismus } \\
\text { und Terrorismus sowie die Gewährleistung der öffentlichen Ordnung und Sicherheit in den Grenzgebieten. }\end{array}$ \\
\hline 11.10 .2018 & $\begin{array}{l}\text { Premierminister Muchammedkalyi Abylgasijew nimmt an der Sitzung des Rats der Regierungschefs der SCO- } \\
\text { Mitgliedsstaaten in Duschanbe teil, die sich mit aktuellen Aspekten der ökonomischen, kulturellen und huma- } \\
\text { nitären Zusammenarbeit auseinandersetzt. }\end{array}$ \\
\hline 11.10 .2018 & $\begin{array}{l}\text { Präsident Dscheenbekow entlässt die Ministerin für Arbeit und soziale Entwicklung, Taalaikul Isakunowa, } \\
\text { sowie zwei ihrer Stellvertreter wegen des Missbrauchs von Diplomatenpässen für Privatreisen und der Verun- } \\
\text { treuung von Geldern. }\end{array}$ \\
\hline 12.10 .2018 & $\begin{array}{l}\text { Wegen eines Streits um gegenseitige Korruptionsvorwürfe treten Außenminister Erlan Abdyldajew und der kir- } \\
\text { gisische Botschafter in Südkorea, Kylytschbek Sultan, zurück. Sultan kündigt zudem an, politisches Asyl im } \\
\text { Ausland zu beantragen. Nachdem Sultan dem Außenministerium Korruption und Missbrauch von Diplomaten- } \\
\text { pässen vorgeworfen hatte, beschuldigte Abdyldajew Sultan seinerseits der Korruption und des Amtsmissbrauchs } \\
\text { und forderte seine Entlassung. Präsident Dscheenbekow ordnet die Untersuchung der Vorwürfe beider Seiten an. }\end{array}$ \\
\hline 13.10 .2018 & $\begin{array}{l}\text { Während seines Arbeitsbesuchs in Duschanbe führt Premierminister Abylgasijew Gespräche mit dem Minis- } \\
\text { terpräsidenten der Volksrepublik China, Li Keqiang, und dem usbekischen Premierminister Abdulla Aripow } \\
\text { über die Intensivierung der jeweiligen bilateralen Zusammenarbeit. }\end{array}$ \\
\hline 17.10 .2018 & $\begin{array}{l}\text { Präsident Dscheenbekow ernennt Tschingis Aidarbekow, der bisher Botschafter in Japan war, zum neuen } \\
\text { Außenminister. }\end{array}$ \\
\hline 18.10 .2018 & $\begin{array}{l}\text { Auf einer Tagung des Rates der Regionalen Antiterrorstruktur (RATS) der SCO in Bischkek übergibt der stell- } \\
\text { vertretende Vorsitzende des Staatlichen Komitees für Nationale Sicherheit, Asylbek Koschobekow, den Vor- } \\
\text { sitz der Organisation an Russland. }\end{array}$ \\
\hline
\end{tabular}


\begin{tabular}{|l|l|} 
18.10.2018 & Kyrtag meldet, dass Premierminister Abylgasijew bei einem Treffen mit dem afghanischen Regierungschef
\end{tabular} Abdullah Abdullah die Zahlung humanitärer Hilfe an die im Pamir lebenden ethnischen Kirgisen erörtert hat.

\section{Tadschikistan}

\begin{tabular}{|c|c|}
\hline 24.9.2018 & $\begin{array}{l}\text { Ein Gericht im Gebiet Chatlon verurteilt einen Mann wegen Anheizens von Spannungen zu einem Jahr Frei- } \\
\text { heitsentzug, der angesichts eines neuen Porträts von Präsident Emomali Rachmon gescherzt hatte, nun werde } \\
\text { man nicht mehr gen Mekka, sondern in Richtung des Porträts beten. }\end{array}$ \\
\hline 24.9.2018 & $\begin{array}{l}\text { Bei der Agentur zur Kontrolle von Drogen werden fast } 248 \mathrm{~kg} \text { Narkotika verbrannt, die in den letzten Monaten } \\
\text { beschlagnahmt worden waren. Nach Angaben der Agentur wurden } 2018 \text { bisher allein } 357,5 \text { kg Heroin vernichtet. }\end{array}$ \\
\hline 24.9.2018 & $\begin{array}{l}\text { Die neu gegründete exiloppositionelle Nationale Allianz Tadschikistans (NAT) gibt sich eine Organisations- } \\
\text { struktur und beschließt die Besetzung der wichtigsten Führungspositionen. Vorsitzender ist Muchiddin Kabiri, } \\
\text { Stellvertreter Alim Schersamonow. }\end{array}$ \\
\hline 24.9.2018 & $\begin{array}{l}\text { Ein Vertreter des Transportministeriums erklärt gegenüber dem tadschikischen Dienst von RFE/RL, dass die } \\
\text { Regierung unverändert am Bau der Eisenbahnstrecke Turkmenistan-Afghanistan-Tadschikistan interessiert } \\
\text { ist. In den Vortagen hatten anderslautende Erklärungen des tadschikischen Botschafters in Usbekistan zu Irri- } \\
\text { tationen in Turkmenistan geführt. }\end{array}$ \\
\hline 26.9.2018 & $\begin{array}{l}\text { Vier in Tadschikistan wegen Extremismus und Beteiligung an Kriegshandlungen im Ausland gesuchte Männer } \\
\text { aus Duschanbe und Umgebung sind nach Angaben des Innenministeriuims ohne Probleme zu ihren Familien } \\
\text { zurückgekehrt. Ihnen war im Vorfeld bei freiwilliger Rückkehr und offensichtlicher Reue Straffreiheit zuge- } \\
\text { sichert worden. }\end{array}$ \\
\hline 26.9.2018 & Präsident Rachmon empfängt den Generalsekretär der GUS, Sergej Lebedjew, zu Gesprächen. \\
\hline 27.9.2018 & $\begin{array}{l}\text { Der Mitarbeiter des Geheimdienstes, der im August im Internet berichtet hatte, dass ihm von offizieller Seite } \\
\text { der Auftrag zur Ermordung von Muhiddin Kabiri erteilt worden sei, teilt über Facebook mit, dass ein Strafver- } \\
\text { fahren gegen ihn wegen Staatsverrats und Preisgabe von Staatsgeheimnissen eröffnet wurde. }\end{array}$ \\
\hline 27.9.2018 & $\begin{array}{l}\text { Im Vorfeld des GUS-Gipfels führt Präsident Rachmon Gespräche mit seinen kirgisischen, kasachstanischen } \\
\text { und moldowischen Amtskollegen Sooronbaj Dscheenbekow, Nursultan Nasarbajew und Igor Dodon sowie } \\
\text { mit dem neuen armenischen Premierminister Nikol Paschinjan. Gemeinsam mit dem usbekischen Präsiden- } \\
\text { ten Schawkat Mirsijojew besucht Rachmon das staatliche Aluminiumkombinat in Tursonsoda (Bezirke unter } \\
\text { republikanischer Verwaltung). }\end{array}$ \\
\hline 28.9.2018 & $\begin{array}{l}\text { Die Staatsoberhäupter der GUS-Staaten unterzeichnen auf ihrem Gipfel in Duschanbe u. a. eine Vereinbarung } \\
\text { über Zusammenarbeit im Bereich der Internetkriminalität. }\end{array}$ \\
\hline 29.9.2018 & $\begin{array}{l}\text { Die Sprecherin des Föderationsrates der RF, Walentina Matwijenko, führt in Duschanbe Gespräche mit dem } \\
\text { Sprecher des Parlaments, Machmadsaid Ubajdullojew, und trifft die aus der RF an tadschikische Schulen ent- } \\
\text { sandten Russischlehrer. }\end{array}$ \\
\hline 1.10 .2018 & $\begin{array}{l}\text { Präsident Rachmon entlässt den Gouverneur des Autonomen Gebietes Berg-Badachschan (GBAO), Schodi- } \\
\text { chon Dschamsched. Seine Aufgaben werden vom bisherigen Leiter der Aga-Khan-Stiftung in Tadschikistan, } \\
\text { Jodgor Fajsow, übernommen. }\end{array}$ \\
\hline 1.10 .2018 & $\begin{array}{l}\text { Die Regierung stellt im laufenden Jahr zusätzliche } 749 \text { Mio. Somoni ( } 80 \text { Mio. US-Dollar) für eine beschleu- } \\
\text { nigte Fertigstellung des Baus des Wasserkraftwerkes von Rogun bereit. }\end{array}$ \\
\hline 2.10 .2018 & $\begin{array}{l}\text { Asia-Plus meldet, dass ab 1.11.2018 auf Regierungsbeschluss die Strompreise in ganz Tadschikistan um } 15 \% \\
\text { angehoben werden. In Duschanbe steigen zum gleichen Zeitpunkt auch die Heizungspreise. }\end{array}$ \\
\hline 3.10 .2018 & $\begin{array}{l}\text { Ein Gericht im türkischen Istanbul erklärt die von der tadschikischen Regierung vorgebrachten Beschuldi- } \\
\text { gungen gegen den Führer der oppositionellen tadschikischen Gruppe 24, Suchrob Safar, für unbegründet und } \\
\text { beschließt seine Freilassung. Safar war im März } 2018 \text { in der Türkei festgenommen worden. Ihm wird in Tad- } \\
\text { schikistan die Führung einer verbotenen Vereinigung und die Planung eines Angriffs auf die verfassungsmä- } \\
\text { ßige Ordnung vorgeworfen. }\end{array}$ \\
\hline 3.10 .2018 & $\begin{array}{l}\text { Der tadschikische Dienst von RFE/RL berichtet, dass die turkmenischen Grenzbehörden begonnen haben, } \\
\text { die sich seit August auf der iranischen Seite seiner Grenzen wegen Nichtabfertigung stauenden tadschikischen } \\
\text { LKW abzufertigen. Von turkmenischer Seite gibt es keine Erklärung für den Boykott. }\end{array}$ \\
\hline 4.10 .2018 & $\begin{array}{l}\text { Vor dem Büro der OSZE in Duschanbe fordern ungefähr } 20 \text { jugendliche Demonstranten ein Ende der Tätig- } \\
\text { keit der Organisation in Tadschikistan. }\end{array}$ \\
\hline
\end{tabular}




\begin{tabular}{|c|c|}
\hline 5.10 .2018 & $\begin{array}{l}\text { Präsident Rachmon wird im Rahmen seines Japanbesuches von Kaiser Akihito zu Gesprächen über die Per- } \\
\text { spektiven der bilateralen Beziehungen empfangen. }\end{array}$ \\
\hline 5.10 .2018 & $\begin{array}{l}\text { Mehrere regimekritische Websites melden unter Berufung auf eine nicht genannte Quelle beim Obersten Gericht, } \\
\text { dass der Führer der verbotenen Partei der Islamischen Wiedergeburt (PIWT), Kabiri, in absentia zu einer lebens- } \\
\text { länglichen Freiheitsstrafe wegen Staatsverrats, versuchter gewaltsamer Machtergreifung, Spionage, Terrorismus, } \\
\text { Organisation einer kriminellen Vereinigung u. a. verurteilt wurde. Die Verhandlungen waren nicht öffentlich. }\end{array}$ \\
\hline 5.10 .2018 & $\begin{array}{l}\text { Die US-Botschaft in Tadschikistan übergibt den Grenztruppen und dem Verteidigungsministerium feierlich } \\
\text { Fahrzeuge und technische Geräte im Wert von } 8 \text { Mio. US-Dollar. }\end{array}$ \\
\hline 6.10 .2018 & $\begin{array}{l}\text { Innenminister Ramason Rachimsoda sowie Vertreter der Inneren Verwaltung des Gebietes Sogd nehmen am } \\
\text { ersten erweiterten Treffen der Innenminister der zentralasiatischen Staaten im kirgisischen Tscholpon-Ata teil, } \\
\text { bei dem über Fragen des Kampfes gegen die organisierte Kriminalität und Cyberkriminalität sowie die Auf- } \\
\text { rechterhaltung der öffentlichen Ordnung in Grenzbezirken geredet wird. Die Innenminister Usbekistans und } \\
\text { Kirgistans unterschreiben einen Plan über Zusammenarbeit im Kampf gegen organisierte Kriminalität und } \\
\text { Extremismus. }\end{array}$ \\
\hline 7.10 .2018 & $\begin{array}{l}\text { Tadschikistan ist nach dem Jemen der zweitgrößte Empfänger von Unterstützung durch das »Zentrum für } \\
\text { Unterstützung und humanitäre Hilfe König Salman von Saudi-Arabien«. Nach Angaben des Leiters des Zen- } \\
\text { trums, der in der Vorwoche Duschanbe besucht hatte, hat das Zentrum in den vergangenen drei Jahren huma- } \\
\text { nitäre Projekte in Höhe von 9,5 Mio. US-Dollar unterstützt. }\end{array}$ \\
\hline 8.10 .2018 & $\begin{array}{l}\text { Ein Gericht in Duschanbe verurteilt den Sohn des ehemaligen Ministers für Energie und Industrialisierung, } \\
\text { Gul Scherali, Dilowar, wegen eines tätlichen Angriffs auf einen Mitarbeiter der Sicherheitskräfte zu fünf Jah- } \\
\text { ren Freiheitsentzug. Der bereits mehrfach wegen gewalttätigen Verhaltens aufgefallene Dilowar hatte in Reak- } \\
\text { tion auf eine Verwarnung wegen Störung des Straßenverkehrs zugeschlagen. }\end{array}$ \\
\hline 8.10 .2018 & $\begin{array}{l}\text { Präsident Rachmon erörtert bei einem Treffen in Duschanbe mit seinem indischen Amtskollegen Ram Nath } \\
\text { Kovind Stand und Perspektiven der bilateralen Zusammenarbeit. Beide Seiten unterzeichnen über } 60 \text { Verträge } \\
\text { und vereinbaren eine engere Zusammenarbeit. Kovind sagt Tadschikistan nichtrückzahlbare finanzielle Unter- } \\
\text { stützung für Entwicklungsprojekte in Höhe von } 20 \text { Mio. US-Dollar zu. }\end{array}$ \\
\hline 9.10 .2018 & $\begin{array}{l}\text { Mehrere Medien melden, dass Usbekistan begonnen habe, die Landminen entlang seiner Grenze zu Tadschi- } \\
\text { kistan zu entfernen. Die in den 1990er Jahren nach offiziellen Angaben gegen das Vordringen von Islamisten } \\
\text { platzierten Minen haben seither } 374 \text { tadschikische Staatsbürger getötet. }\end{array}$ \\
\hline 10.10 .2018 & $\begin{array}{l}\text { Der tadschikische Dienst von RFE/RL berichtet, dass der IWF seine Bereitschaft zur Realisierung eines weite- } \\
\text { ren Unterstützungsprogrammes an die Durchführung einer Reihe von Reformen im wirtschaftlichen Bereich } \\
\text { binde, u. a. die Schließung von zwei zahlungsunfähigen Banken. }\end{array}$ \\
\hline 10.10 .2018 & $\begin{array}{l}\text { Die untere Kammer des Parlamentes beschließt, dass alle gesellschaftlichen Vereinigungen in Zukunft öffent- } \\
\text { lich Rechenschaft über die Inanspruchnahme von Finanzhilfen in- wie ausländischer Organisationen ablegen } \\
\text { müssen. Die Änderung des Gesetzes über gesellschaftliche Vereinigungen soll den Empfehlungen der Finan- } \\
\text { cial Action Task Force on Money Laundering (FATF) entsprechen. }\end{array}$ \\
\hline 11.10 .2018 & $\begin{array}{l}\text { Präsident Rachmon erörtert im Vorfeld des SCO-Gipfels mit dem amtierenden afghanischen Regierungschef } \\
\text { Abdullah Abdullah die regionale und internationale Lage und empfängt den den chinesischen Premierminis- } \\
\text { ter Li Keqiang im informellen Rahmen zu Gesprächen. }\end{array}$ \\
\hline 12.10 .2018 & $\begin{array}{l}\text { Die Regierungschefs der SCO-Mitgliedsstaaten beraten in Duschanbe über die Weiterentwicklung der wirt- } \\
\text { schaftlichen und humanitären Zusammenarbeit sowie über das Programm und Budget der SCO für das Jahr } \\
\text { 2019. Präsident Rachmon empfängt am Rande des Treffens den russischen Premierminister Dmitrij Medwed- } \\
\text { jew und seinen weißrussischen Amtskollegen Sergej Rumas zu Gesprächen. }\end{array}$ \\
\hline 15.10 .2018 & $\begin{array}{l}\text { Der Chef des Pressezentrums des Zolldienstes, Fachriddin Sobirow, erliegt den schweren Verletzungen, mit } \\
\text { denen er zwei Tage zuvor im Zentrum von Duschanbe aufgefunden worden war. Verwandte sprechen von einem } \\
\text { Überfall, nach Darstellung des Innenministeriums hat sich Sobirow bei einem Sturz selber verletzt. }\end{array}$ \\
\hline 16.10 .2018 & $\begin{array}{l}\text { Der russische Innenminister Wladimir Kolokolzew führt in Duschanbe Gespräche mit seinem tadschikischen } \\
\text { Amtskollegen Rachimsoda über eine verstärkte Zusammenarbeit im Kampf gegen Terrorismus, Drogenhan- } \\
\text { del und grenzüberschreitende Kriminalität. }\end{array}$ \\
\hline 19.10 .2018 & $\begin{array}{l}\text { An der Grenze zu Usbekistan im Bezirk Schamsiddin Schochni (Gebiet Chatlon) wird ein junger Mann bei } \\
\text { der Jagd durch eine Antipersonenmine getötet, ein weiterer schwer verletzt. }\end{array}$ \\
\hline 19.10 .2018 & $\begin{array}{l}\text { Bei einer Explosion in einer pyrotechnischen Fabrik im russischen Gebiet Leningrad kommen vier tadschiki- } \\
\text { sche Arbeitsmigranten ums Leben. }\end{array}$ \\
\hline
\end{tabular}




\section{Turkmenistan}

\begin{tabular}{|c|c|}
\hline 24.9.2018 & $\begin{array}{l}\text { Die Regierung beschließt drei Tage vor dem Unabhängigkeitstag die Amnestie von } 1.722 \text { Menschen. Die eigent- } \\
\text { lich für diesen Tag geplante Sitzung des Volksrates (Halk Maslachaty), des obersten gesetzgebenden Organs } \\
\text { Turkmenistans, wird aus unbekannten Gründen auf den 25.9.2018 verschoben. }\end{array}$ \\
\hline 25.9.2018 & $\begin{array}{l}\text { Auf der Sitzung des Volksrats kündigt Präsident Gurbanguly Berdymuchammedow die Einführung von Gebüh- } \\
\text { ren für die bisher kostenlosen kommunalen Dienstleistungen wie Wasser, Strom und Gas ab } 2019 \text { wegen der } \\
\text { veränderten wirtschaftlichen Situation und knapper werdenden Ressourcen an. Darüber hinaus gibt er zu, dass } \\
\text { es Effizienzprobleme in der Landwirtschaft gibt. }\end{array}$ \\
\hline 26.9.2018 & $\begin{array}{l}\text { Der turkmenische Dienst von RFE/RL meldet, dass Bürger, die ihre Ferien im Ausland verbracht oder größere } \\
\text { Anschaffungen, wie z. B. einen Autokauf, getätigt haben, ins Ministerium für nationale Sicherheit vorgeladen } \\
\text { werden, um eine Erklärung über ihre Einkommensquellen abzugeben und sie ggfs. mit Nachweisen zu belegen. }\end{array}$ \\
\hline 27.9.2018 & $\begin{array}{l}\text { Präsident Berdymuchammedow verleiht dem Schwiegersohn seiner älteren Schwester Gulnabat Dowletowa, } \\
\text { Ibabekir Bekdurdijew, anlässlich des 27. Jahrestag der Unabhängigkeit Turkmenistans die Medaille Für die } \\
\text { Liebe zum Vaterland. Bekdurdijew, der vor allem für seine Leidenschaft für teure Uhren bekannt ist, wird für } \\
\text { seinen Beitrag zur Verbesserung des internationalen Prestiges Turkmenistans gewürdigt. }\end{array}$ \\
\hline 28.9.2018 & $\begin{array}{l}\text { Präsident Berdymuchammedow nimmt als einziger Präsident nicht am jährlichen Treffen der Staatsoberhäup- } \\
\text { ter der GUS-Mitgliedsstaaten in Duschanbe teil, sondern schickt lediglich Vize-Premierminister Purli Aga- } \\
\text { muradow. Turkmenistan übernimmt } 2019 \text { den Vorsitz der Organisation. }\end{array}$ \\
\hline 1.10 .2018 & $\begin{array}{l}\text { Vor dem Hauptgebäude der UN in New York findet eine Protestaktion gegen Zwangsarbeit während der Baum- } \\
\text { wollernte in Turkmenistan statt, die von der internationalen Cotton Campaign anlässlich der Teilnahme Prä- } \\
\text { sident Berdymuchammdows an der UN-Vollversammlung organisiert wurde. }\end{array}$ \\
\hline 3.10 .2018 & $\begin{array}{l}\text { Der turkmenische Dienst von RFE/RL meldet, dass die tadschikischen Lastwagen, die seit Ende August die- } \\
\text { ses Jahres an der turkmenisch-iranischen Grenze feststecken, eine Transiterlaubnis der turkmenischen Zoll- } \\
\text { und Grenzbehörden erhalten haben und sich die Schlangen langsam auflösen würden. }\end{array}$ \\
\hline 3.10 .2018 & $\begin{array}{l}\text { Eine turkmenische Delegation unter Leitung des stellvertretenden Außenministers Wepa Chadschijew stellt auf } \\
\text { der } 46 . \text { Sitzung des UN-Ausschusses für wirtschaftliche, soziale und kulturelle Rechte (CESCR) den turkmeni- } \\
\text { schen Bericht über die Umsetzung des Internationalen Pakts über wirtschaftliche, soziale und kulturelle Rechte } \\
\text { vor. Im Vordergrund der anschließenden Diskussion stehen u. a. Fragen der Gleichberechtigung von Mann und } \\
\text { Frau, Schutz der Familie, körperliche, soziale und psychische Gesundheit, Bildung sowie kulturelle Rechte. }\end{array}$ \\
\hline 5.10 .2018 & $\begin{array}{l}\text { Bei einem Treffen der Generalversammlung der Asia-Pacific Broadcasting Union in Aschgabat wird Präsident } \\
\text { Berdymuchammedow ein Preis für die Entwicklung der Medien in der Region und die Integration in den glo- } \\
\text { balen Informationsraum verliehen. (Turkmenistan nimmt im Ranking der Pressefreiheit der Organisation } \\
\text { Reporter ohne Grenzen Platz } 178 \text { von } 180 \text { Ländern ein). }\end{array}$ \\
\hline 5.10 .2018 & $\begin{array}{l}\text { Präsident Berdymuchammedow unterzeichnet ein Dekret, das die staatlichen Einkaufspreise für Weizen und } \\
\text { Baumwolle erhöhen soll, um die Produzenten unterstützen. Aus der offiziellen Meldung geht nicht hervor, wie } \\
\text { stark die Preise steigen werden. }\end{array}$ \\
\hline 8.10 .2018 & $\begin{array}{l}\text { Eine Delegation des IWF, die Turkmenistan vom 1.-5.10.2018 besucht hatte, um die makroökonomische und } \\
\text { finanzielle Situation im Land zu untersuchen, begrüßt in ihrer Abschlusserklärung die Abschaffung der kos- } \\
\text { tenlosen Gas-, Strom- und Wasserversorgung, die dazu beitragen werde, staatliche Ressourcen zu sparen und } \\
\text { eine effizientere Nutzung von Energie- und Wasserressourcen zu fördern. }\end{array}$ \\
\hline 9.10 .2018 & $\begin{array}{l}\text { In einem Interview mit dem staatlichen Fernsehsender während seines Besuchs in Aschgabat kündigt der } \\
\text { Vorstandsvorsitzende von Gazprom, Aleksei Miller, an, dass sein Unternehmen ab Januar } 2019 \text { wieder Gas aus } \\
\text { Turkmenistan importieren wird. Russland hatte seine Erdgasimporte aus Turkmenistan vor drei Jahren gestoppt. }\end{array}$ \\
\hline 10.10 .2018 & $\begin{array}{l}\text { Der turkmenische Dienst von RFE/RL berichtet, dass die Preise für Postdienstleistungen bereits am 1.10.2018 } \\
\text { um } 60 \% \text { gestiegen seien. Darüber hinaus gebe es seit Kurzem nicht mehr genug Flugtickets für internationale } \\
\text { Flüge, insbesondere nach Russland, Belarus und in die Türkei. }\end{array}$ \\
\hline 11.10 .2018 & $\begin{array}{l}\text { Eine Delegation unter der Leitung von Außenminister Raschid Meredow führt in Brüssel Gespräche mit der } \\
\text { Hohen Vertreterin der EU für Außen- und Sicherheitspolitik, Federica Mogherini, und Vertretern der EU- } \\
\text { Kommission über die Wiederbelebung der Energiezusammenarbeit, regionale Sicherheit und die Entwicklung } \\
\text { von Verkehrs- und Transitrouten, die Zentralasien mit europäischen Ländern verbinden. }\end{array}$ \\
\hline
\end{tabular}




\begin{tabular}{|l|l|}
\hline 15.10.2018 & $\begin{array}{l}\text { Der turkmenische Dienst von RFE/RL berichtet von wiederholten nicht öfentlich angekündigten Flügen } \\
\text { des Flugzeugs des Präsidenten nach Deutschland. So soll Berdymuchammedows Boeing 737 in diesem Jahr } \\
\text { bereits sechs Mal in Deutschland gelandet und nach maximal 2,5 Stunden Aufenthalt zurückgeflogen sein. } \\
\text { Gründe für die kurzen Besuche und ob sich der Präsident oder eine offizielle Delegation an Bord befanden, } \\
\text { sind nicht bekannt. }\end{array}$ \\
\hline 15.10 .2018 & $\begin{array}{l}\text { Chronika Turkmenistana berichtet, dass immer mehr Turkmenen wegen des Fehlens von Grundnahrungsmit- } \\
\text { teln und massiver Preissteigerungen in den letzten Monaten emigriert seien und deshalb in diversen Städten } \\
\text { des Landes zunehmend Häuser leer stünden. Genaue Zahlen werden nicht genannt. }\end{array}$ \\
\hline 18.10 .2018 & $\begin{array}{l}\text { Eine Delegation des Außenministeriums unter Leitung von Außenminister Meredow nimmt an politischen } \\
\text { Konsultationen im Außenministerium von Aserbaidschan in Baku teil. Meredow und sein aserbaidschanischer } \\
\text { Amtskollege Elmar Mammadjarow unterzeichnen ein außenpolitisches Kooperationsprogramm für 2019/20. }\end{array}$ \\
\hline 19.10 .2018 & $\begin{array}{l}\text { Der turkmenische Dienst von RFE/RL meldet, dass die Redaktion zunehmend Beschwerden über den Ver- } \\
\text { kauf bereits abgelaufener Lebensmittel in Supermärkten erhalte. Im Gebiet Daschogus soll es bereits seit drei } \\
\text { Tagen kein Mehl mehr in staatlichen Lebensmittelläden geben. }\end{array}$ \\
\hline
\end{tabular}

\section{Usbekistan}

\begin{tabular}{|c|c|}
\hline 24.9.2018 & $\begin{array}{l}\text { Präsident Schawkat Mirsijojew empfängt den Vorsitzenden der Großen Nationalversammlung der Türkei, } \\
\text { Binali Yildirim, zu Gesprächen über die Rolle der Parlamente bei der Stärkung der bilateralen Beziehungen. } \\
\text { Yildirim und eine Delegation türkischer Abgeordneter führen auch Gespräche mit dem Sprecher der unteren } \\
\text { Kammer des Parlaments, Nurdindschon Ismailow. }\end{array}$ \\
\hline 25.9.2018 & $\begin{array}{l}\text { UN-Generalsekretär António Guterres nennt in seiner Rede vor der UN-Vollversammlung Usbekistan als posi- } \\
\text { tives Beispiel für eine verstärkte regionale Zusammenarbeit und einen friedlichen Machtwechsel. }\end{array}$ \\
\hline 25.9 .2018 & $\begin{array}{l}\text { Beim Ministerkabinett wird die Stiftung El-jurt Umidi (Hoffnung der Nation) gebildet, die der Ausbildung } \\
\text { von Experten im Ausland dienen soll. }\end{array}$ \\
\hline 26.9.2018 & $\begin{array}{l}\text { Der bekannte Menschenrechtler Talib Jakubow, der mehr als zehn Jahre im Exil in Frankreich gelebt hatte, } \\
\text { ist laut Bericht von RFE/RL ohne Probleme nach Usbekistan zurückgekehrt. Der 78-jährige Gründer der } \\
\text { "Menschenrechtsgesellschaft Usbekistans« war } 2007 \text { aus seiner Heimat geflüchtet und hat die französische } \\
\text { Staatsbürgerschaft. }\end{array}$ \\
\hline 27.9.2018 & $\begin{array}{l}\text { Der Senat verabschiedet das Gesetz über private Arbeitsagenturen, das privaten Firmen die Entsendung von } \\
\text { Arbeitskräften ins Ausland erlaubt. }\end{array}$ \\
\hline 28.9.2018 & $\begin{array}{l}\text { Präsident Mirsijojew nimmt am Gipfel der Staatschefs der GUS-Mitgliedsstaaten in Duschanbe teil, auf dem } \\
\text { über den Ausbau der multilateralen Zusammenarbeit beraten wird. Gemeinsam mit seinem tadschikischen } \\
\text { Amtskollegen Emomali Rachmon besucht Mirsijojew das staatliche Aluminiumwerk TALCO in Tursonsoda } \\
\text { (Bezirke unter republikanischer Verwaltung). }\end{array}$ \\
\hline 28.9.2018 & $\begin{array}{l}\text { Im russischen Nischnij Nowgorod wird ein usbekischer Staatsbürger unter dem Verdacht der Beteiligung an } \\
\text { Kampfhandlungen im Donbass auf Seiten der Separatisten verhaftet. }\end{array}$ \\
\hline 29.9 .2018 & $\begin{array}{l}\text { Ab sofort gibt es ein Statut für die staatliche Registrierung von religiösen Organisationen, in dem Fristen und } \\
\text { vorzulegende Dokumente definiert sind. Bislang waren Ablauf und Entscheidungsgrundlagen des Komitees } \\
\text { für religiöse Angelegenheiten nicht juristisch geregelt. }\end{array}$ \\
\hline 30.9 .2018 & $\begin{array}{l}\text { Die US-Staatsanwaltschaft fordert im Prozess gegen Sajfullo Saipow die Todesstrafe. Der usbekische Staats- } \\
\text { bürger soll im Oktober } 2017 \text { in New York mit einem LKW absichtlich in eine Menschenmenge gefahren sein } \\
\text { und dabei acht Menschen getötet und viele weitere schwer verletzt haben. Der bekennende Anhänger des IS } \\
\text { war } 2010 \text { mit einer gewonnenen Green Card in die USA eingereist. }\end{array}$ \\
\hline 30.9 .2018 & $\begin{array}{l}\text { Der Vorstand der EBRD verabschiedet die neue Strategie für Usbekistan 2018-2023, mit der die Konkurrenz- } \\
\text { fähigkeit des Landes durch Stärkung des Privatsektors gesteigert, Green Economy und effiziente Nutzung von } \\
\text { Ressourcen sowie regionale und internationale Zusammenarbeit gefördert werden sollen. }\end{array}$ \\
\hline 1.10 .2018 & $\begin{array}{l}\text { Der russische Kommersant meldet, dass ein im August } 2017 \text { im Gebiet Moskau verhafteter usbekischer Staats- } \\
\text { bürger wegen der Beteiligung am Syrienkrieg zu einer 15-jährigen Freiheitsstrafe verurteilt wurde. }\end{array}$ \\
\hline 1.10 .2018 & $\begin{array}{l}\text { Präsident Mirsijojew wird in Neu-Dehli von seinem indischen Amtskollegen Ram Nath Kovind, Premiermi- } \\
\text { nister Narenda Modi und dem Vorsitzenden des Parlamentes, Venkaiah Naidu, zu Gesprächen über verschie- } \\
\text { denste Aspekte der bilateralen Beziehungen empfangen. }\end{array}$ \\
\hline
\end{tabular}




\begin{tabular}{|c|c|}
\hline 2.10 .2018 & $\begin{array}{l}\text { Im kirgisischen Kysyl-Kija (Gebiet Batken) endet eine weitere, mehrwöchige Verhandlungsphase usbekischer } \\
\text { und kirgisischer Arbeitsgruppen zur Delimitierung und Demarkation der gemeinsamen Grenze. }\end{array}$ \\
\hline 2.10 .2018 & $\begin{array}{l}\text { Komil Allamdschonow wird von seinen Posten als Sprecher des Präsidenten und stellvertretendem Leiter der } \\
\text { Präsidialadministration entlassen. Gründe werden nicht genannt. }\end{array}$ \\
\hline 2.10 .2018 & $\begin{array}{l}\text { Bildungsminister Schersod Schermatow führt in Washington Gespräche mit seiner Amtskollegin Elizabeth } \\
\text { Davos über Zusammenarbeit im Bildungsbereich und die Implementierung bereits bestehender Vereinbarungen. }\end{array}$ \\
\hline 2.10 .2018 & $\begin{array}{l}\text { Fergananews berichtet, dass Iman Karimowa, die Tochter der skandalumwitterten Tochter des verstorbenen } \\
\text { Präsidenten Islam Karimow, Gulnara, vor einigen Tagen Taschkent Richtung London verlassen habe. Sie soll } \\
\text { über soziale Netzwerke auch mitgeteilt haben, dass ihre Mutter »zuhause« sei, was die Generalstaatsanwalt- } \\
\text { schaft umgehend dementiert. }\end{array}$ \\
\hline 3.10 .2018 & $\begin{array}{l}\text { Im Rahmen eines Business Forum mit Vertretern der Wirtschaft Usbekistans und der VAE wird eine Ver- } \\
\text { einbarung über die Schaffung eines Direktinvestitionsfonds mit der Gesamtsumme von } 1 \text { Mrd. US-Dollar } \\
\text { unterzeichnet. }\end{array}$ \\
\hline 3.10 .2018 & $\begin{array}{l}\text { Der usbekische Dienst von RFE/RL berichtet, dass es am Morgen des 27.9.2018 im größten Industriebetrieb } \\
\text { des Ferganatals, einer privaten Zementfabrik in Kuwasai (Gebiet Fergana), einen ca. zweistündigen Streik im } \\
\text { Zusammenhang mit Massenentlassungen gegeben hat. }\end{array}$ \\
\hline 5.10 .2018 & $\begin{array}{l}\text { Usbekistan führt ab sofort die Visafreiheit für französische Staatsbürger für einen Aufenthalt von bis zu } 30 \\
\text { Tagen ein. }\end{array}$ \\
\hline 5.10 .2018 & $\begin{array}{l}\text { Bei einem schweren Unfall auf einer Baustelle im Westen von Moskau kommen acht Menschen, darunter zwei } \\
\text { usbekische Staatsbürger, ums Leben. }\end{array}$ \\
\hline 6.10 .2018 & $\begin{array}{l}\text { Innenminister Pulat Bobodschonow sowie Vertreter der Inneren Verwaltung der Gebiete Andischan, Naman- } \\
\text { gan und Fergana nehmen am ersten erweiterten Treffen der Innenminister der zentralasiatischen Staaten im } \\
\text { kirgisischen Tscholpon-Ata teil, bei dem über Fragen des Kampfes gegen die organisierte Kriminalität und } \\
\text { Cyberkriminalität sowie die Aufrechterhaltung der öffentlichen Ordnung in Grenzbezirken geredet wird. Die } \\
\text { Innenminister Usbekistans und Kirgistans unterschreiben einen Plan über Zusammenarbeit im Kampf gegen } \\
\text { organisierte Kriminalität und Extremismus. }\end{array}$ \\
\hline 8.10 .2018 & $\begin{array}{l}\text { Der Sonderbeauftragte des Präsidenten für Afghanistan, Ismatilla Irgaschew, trifft in Berlin mit dem Sonder- } \\
\text { beauftragten der Bundesregierung für Afghanistan und Pakistan, Markus Potzel, zu Gesprächen zusammen. }\end{array}$ \\
\hline 8.10 .2018 & $\begin{array}{l}\text { Ein Gericht in Taschkent verurteilt die beiden Brüder Schuchrat und Abrol Dusmuchamedow sowie Schura- } \\
\text { boj Satibaldijew zu sechseinhalb, bzw. sieben Jahren Haft wegen Zugehörigkeit zur extremistischen Strömung } \\
\text { der Dschihadisten. Die Brüder Dusmuchamedow hatten seit } 2013 \text { in der Türkei im Exil gelebt und waren nach } \\
\text { Zusicherung von Straffreiheit im Mai } 2018 \text { nach Usbekistan zurückgekehrt, wo sie trotz Mirsijojews Amnes- } \\
\text { tieversprechen verhaftet worden waren. }\end{array}$ \\
\hline 8.10 .2018 & $\begin{array}{l}\text { Präsident Mirsijojew trifft während seines Frankreichbesuches mit der Generaldirektorin der UNESCO, } \\
\text { Audrey Azoulay, zu Gesprächen zusammen. Beide Seiten unterzeichnen ein Kooperationsprogramm bis } 2021 .\end{array}$ \\
\hline 9.10 .2018 & $\begin{array}{l}\text { Präsident Mirsijojew wird in Paris von seinem französischen Amtskollegen Emmanuel Macron zu Gesprächen } \\
\text { über Stand und Perspektiven der bilateralen Zusammenarbeit insbesondere im Bereich der Wirtschaft emp- } \\
\text { fangen. Zuvor war Mirsijojew bereits mit dem Vorsitzenden des Senats, Gérard Larcher, sowie Vertretern der } \\
\text { größten französischen Unternehmen zusammengetroffen. Im Vorfeld des Besuches wurden Vereinbarungen } \\
\text { über Investitionsprojekte im Wert von } 5 \text { Mrd. Euro unterzeichnet. }\end{array}$ \\
\hline 9.10 .2018 & $\begin{array}{l}\text { Mehrere Medien melden, dass Usbekistan begonnen habe, die Landminen entlang seiner Grenze zu Tadschi- } \\
\text { kistan zu entfernen. Sie waren in den 90er Jahren aus Angst vor dem Vordringen von Islamisten aus Tadschi- } \\
\text { kistan gelegt worden. }\end{array}$ \\
\hline 11.10 .2018 & $\begin{array}{l}\text { Präsident Mirsijojew empfängt den Großimam von Ägypten und Scheich der Al-Azhar, Ahmed Mohammed } \\
\text { Ahmed al-Tayeb, zu Gesprächen über Stand und Perspektiven der Zusammenarbeit. }\end{array}$ \\
\hline 12.10 .2018 & $\begin{array}{l}\text { In Taschkent findet die 75. Sitzung des Rates der Verteidigungsminister der GUS-Staaten statt. Am Rande } \\
\text { der Sitzung unterzeichnen die Verteidigungsminister Usbekistans und der RF, Abdusalom Asisiow und Sergej } \\
\text { Schoigu, einen Vertrag über die Nutzung des Luftraumes beider Staaten für die Luftwaffe. }\end{array}$ \\
\hline
\end{tabular}




\begin{tabular}{|l|l|}
\hline 17.10 .2018 & $\begin{array}{l}\text { Die Europäische Investitionsbank (EIB) bewilligt zwei Darlehen in Höhe von je 100 Mio. Euro zur Verbes- } \\
\text { serung der Wasserversorgung und für Investitionen zur effektiven Energienutzung. Nach Angaben der Bank } \\
\text { handelt es sich um die ersten konkreten Projekte im Rahmen einer neu gestalteten Zusammenarbeit mit Usbe- } \\
\text { kistan. Zwei Tage zuvor hatte die EBRD einen Vertrag über einen 20 Mio. US-Dollar Kredit mit der Impak } \\
\text { Juli Bank unterzeichnet. }\end{array}$ \\
\hline 17.10 .2018 & $\begin{array}{l}\text { Eine Gruppe von Menschenrechtlern, die vor der Botschaft der RF gegen Menschenrechtsverletzungen in } \\
\text { Usbekistan protestiert und den russischen Präsidenten Putin um Unterstützung bittet, wird festgenommen. }\end{array}$ \\
\hline 18.10 .2018 & $\begin{array}{l}\text { In Moskau wird in der Nähe der Botschaft Usbekistans feierlich ein Denkmal des ehemaligen usbekischen Prä- } \\
\text { sidenten Islam Karimow enthüllt. Unter den ca. 200 Gästen befinden sich u. a. der Sprecher des Senats, Nig- } \\
\text { matulla Juldaschew, und die Ehefrau des ehemaligen Staatsoberhauptes, Tatjana Karimowa. }\end{array}$ \\
\hline 18.10 .2018 & $\begin{array}{l}\text { Der Sekretär des Sicherheitsrates, Wiktor Machmudow, trifft in Moskau mit seinem russischen Amtskollegen } \\
\text { Nikolai Patruschew zu Gesprächen über Fragen der Zusammenarbeit in den Bereichen Militär, Sicherheit und } \\
\text { Migration zusammen. }\end{array}$ \\
\hline 19.10 .2018 & $\begin{array}{l}\text { Der russische Präsident Wladimir Putin wird in Taschkent von seinem Amtskollegen Mirsijojew zu Gesprächen } \\
\text { über eine Stärkung der strategischen Partnerschaft zwischen beiden Ländern sowie die Intensivierung der Zusam- } \\
\text { menarbeit in vielen Bereichen empfangen. Beide Staatsoberhäupter geben per Videokonferenz das Startsignal } \\
\text { für den Bau des von Russland errichteten ersten Atomkraftwerkes Usbekistans und unterzeichnen eine Reihe } \\
\text { von Kooperationsvereinbarungen. Nach Angaben des Wirtschaftsministeriums wurden bei einem gleichzeitig } \\
\text { stattfindenden Wirtschaftsforum Verträge im Wert von insgesamt mehr als 27 Mrd. US-Dollar unterzeichnet. }\end{array}$ \\
\hline
\end{tabular}

Sie können die gesamte Chronik seit 2008 auch auf <http://www.laender-analysen.de/zentralasien/> unter dem Link "Chronik«lesen.

Herausgeber:

Zentrum für Osteuropa- und internationale Studien (ZOiS) gGmbH Deutsche Gesellschaft für Osteuropakunde e.V.

Deutsches Polen-Institut

Forschungsstelle Osteuropa an der Universität Bremen

Leibniz-Institut für Agrarentwicklung in Transformationsökonomien

Leibniz-Institut für Ost- und Südosteuropaforschung

Redaktion:

Dr. Beate Eschment (verantwortlich)

Redaktionsassistenz: Ann-Sophie Gast

Satz: Matthias Neumann

Wissenschaftlicher Beirat:

Dr. Luca Anceschi, University of Glasgow

Prof. Dr. Martin Petrick, Leibniz-Institut für Agrarentwicklung in Transformationsökonomien, Halle

Die Meinungen, die in den Zentralasien-Analysen geäußert werden, geben ausschließlich die Auffassung der Autoren wieder. Abdruck und sonstige publizistische Nutzung sind nach Rücksprache mit der Redaktion gestattet.

Zentralasien-Analysen-Layout: Matthias Neumann, nach einen Konzept von Cengiz Kibaroglu, mit einer Grafik von Sebastian Klüsener

Alle Ausgaben der Zentralasien-Analysen sind mit Themen- und Autorenindex archiviert unter www.laender-analysen.de

ISSN 1866-2110 @ 2018 by Zentrum für Osteuropa- und internationale Studien (Z0iS) gGmbH, Deutsche Gesellschaft für Osteuropakunde e.V. Deutsches Polen-Institut, Forschungsstelle Osteuropa an der Universität Bremen, Leibniz-Institut für Agrarentwicklung in Transformationsökonomien, Leibniz-Institut für Ost- und Südosteuropaforschung

Zentrum für Osteuropa- und internationale Studien (Z0is) gGmbH • Mohrenstraße 60 • 10117 Berlin • Telefon: + 49 (30) 2005949-20

e-mail: beate.eschment@zois-berlin.de•Internet-Adresse: www.laender-analysen.de/zentralasien 


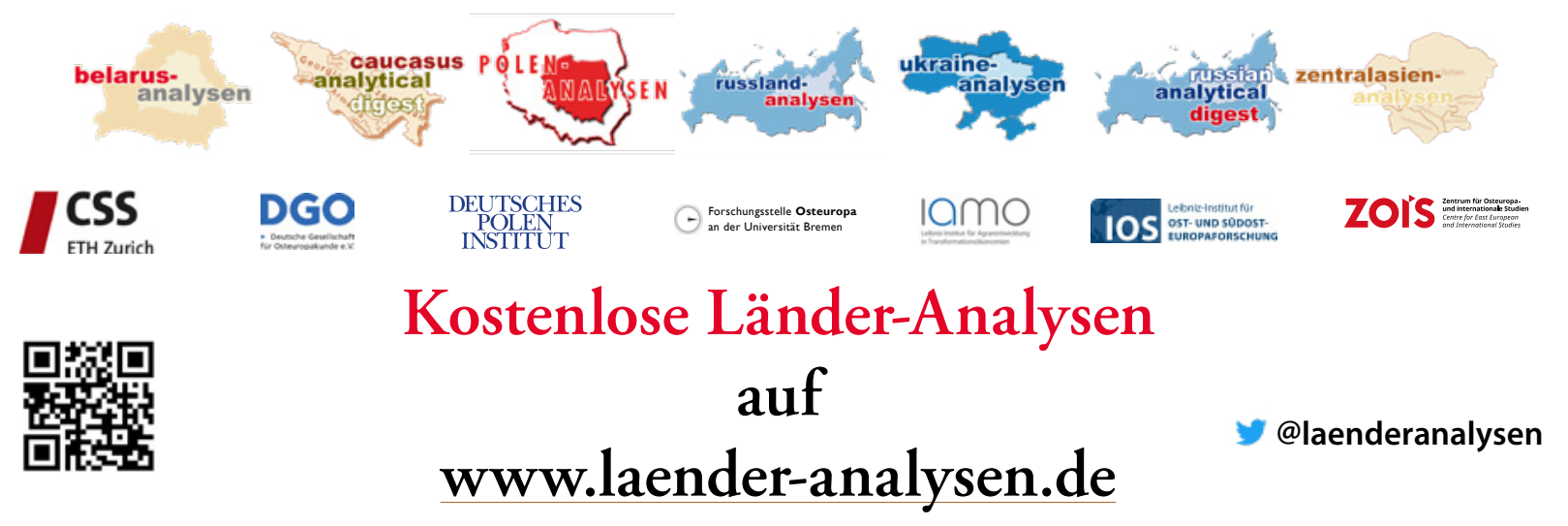

Die Länder-Analysen bieten regelmäßig im kostenlosen Abonnement kompetente Einschätzungen aktueller politischer, wirtschaftlicher, sozialer und kultureller Entwicklungen in Ostmitteleuropa und der GUS. Alle Länder-Analysen verstehen sich als Teil eines gemeinsamen Projektes, das der wissenschaftlich fundierten, allgemeinverständlich formulierten Analyse der Entwicklungen im östlichen Europa, der Offenheit für verschiedene inhaltliche Positionen und der kostenlosen und nicht-kommerziellen Information einer breit verstandenen interessierten Öffentlichkeit verpflichtet ist. Autor/innen sind internationale Fachwissenschaftler/innen und Expert/innen. Die Redaktionen der Länder-Analysen bestehen aus Wissenschaftler/innen mit langjähriger Forschungserfahrung.

Die deutschsprachigen Länder-Analysen werden gemeinsam von der Forschungsstelle Osteuropa an der Universität Bremen, dem Zentrum für Osteuropa- und internationale Studien, der Deutschen Gesellschaft für Osteuropakunde, dem Deutschen Polen-Institut, dem Leibniz-Institut für Agrarentwicklung in Transformationsökonomien und dem Leibniz-Institut für Ost- und Südosteuropaforschung herausgegeben. Die englischsprachigen Länder-Analysen erscheinen in Kooperation der Forschungsstelle Osteuropa mit dem Center for Security Studies (CSS) der ETH Zürich.

Die Länder-Analysen bieten regelmäßig Kurzanalysen zu aktuellen Themen, ergänzt um Grafiken und Tabellen sowie Dokumentationen. Zusätzlich gibt es eine Chronik aktueller Ereignisse. Alle Länder-Analysen sind auch mit Archiv und Indizes online verfügbar unter $<$ www.laender-analysen.de $>$.

\section{Belarus-Analysen}

Erscheinungsweise: zweimonatlich

Abonnement unter: <http://www.laender-analysen.de/belarus/>

\section{Caucasus Analytical Digest}

In englischer Sprache. Erscheinungsweise: monatlich

Abonnement unter: <http://www.css.ethz.ch/en/publications/cad.html>

\section{Polen-Analysen}

Erscheinungsweise: zweimal monatlich

Abonnement unter: <http://www.deutsches-polen-institut.de/newsletter/polen-analysen/>

Auch als App für Android ${ }^{\mathrm{TM}}$ (ab Januar 2016) kostenlos auf Google Play ${ }^{\mathrm{TM}}$.

\section{Russland-Analysen}

Erscheinungsweise: zweiwöchentlich

Abonnement unter: <http://www.laender-analysen.de/russland/>

Auch als App für Android (ab Januar 2016) kostenlos auf Google Play.

\section{Russian Analytical Digest}

In englischer Sprache. Erscheinungsweise: zweimal monatlich

Abonnement unter: $<$ http://www.css.ethz.ch/en/publications/rad.html>

\section{Ukraine-Analysen}

Erscheinungsweise: zweimal monatlich

Abonnement unter: <http://www.laender-analysen.de/ukraine/>

Auch als App für Android (ab Januar 2016) kostenlos auf Google Play.

\section{Zentralasien-Analysen}

Erscheinungsweise: monatlich

Abonnement unter: <http://www.laender-analysen.de/zentralasien/>

Auch als App für Android (ab Januar 2016) kostenlos auf Google Play.

Google Play, das Google Play-Logo und Android sind Marken von Google Inc. TWITTER, TWEET, RETWEET und das Twitter Logo sind eingetragene Markenzeichen von Twitter, Inc. oder angeschlossenen Unternehmen. Der Android-Roboter wird auf der Grundlage von einem Werk wiedergegeben oder modifiziert, das von Google erstellt und geteilt und gemäß den Bedingungen der Creative Commons 3.0 Attribution-Lizenz verwendet wird. 